\title{
Addicted to Debt: \\ Foreign Purchases of U.S. Treasuries and the Term-Premium
}

\author{
David Kohn \\ Universidad Torcuato Di Tella
}

February, 2015

\begin{abstract}
In this paper, I study the quantitative effect of purchases of U.S. Treasury bonds and notes by foreigners on long-term yields and the term-premium over the recent decade. I set up a consumption-based model with habit preferences, calibrate it to match the average slope of the yield curve in the U.S., and find that foreign purchases decreased long-term yields significantly over this period. A third of this change is explained by a drop in the term-premium: in the model, foreign purchases increase consumption with respect to a reference level or habit, which reduces the agent's risk-aversion, therefore decreasing the term-premium. Finally, I show that a reversal of foreign inflows results in a sharp increase in long-term yields.

Key words: term-premium, long-term yields, U.S. Treasury bonds, foreign official institutions, habits.

JEL Classification: E43, E44, G12, G15.

\footnotetext{
* Email: dkohn@utdt.edu. Mailing address: Universidad Torcuato Di Tella, Departamento de Economia, Av. Figueroa Alcorta 7350, Buenos Aires, Argentina, C1428BCW. I would like to thank Jaroslav Borovička, Tim Cogley, Sydney Ludvigson, and Stijn Van Nieuwerburgh for their advice and invaluable comments and suggestions. I would also like to thank Virgiliu Midrigan, Matteo Maggiori, Michal Szkup, Fernando Leibovici, Gaston Navarro, Elena Resk, and Aitor Erce for their helpful feedback and suggestions.
} 


\section{Introduction}

Over the last two decades there has been a dramatic increase in foreign holdings of U.S. Treasuries. From 1994 to 2013, foreign ownership of U.S. Treasury bills, notes and bonds, increased from 18 percent to 49 percent of total outstanding treasury debt, with holdings representing 33.6 percent of GDP by the end of that period ${ }^{1}$ Approximately three-fourths of this increase was driven by Foreign Official Institutions, such as central banks. At the same time, both nominal and real long-term bond yields declined significantly. Figure 1 depicts the increase in the ratio of foreign holdings to GDP and the decline in the yield of a 10-year nominal U.S. Treasury bond. In this paper, I study the extent to which the rise in foreign holdings of U.S. treasuries drove the fall in long-term yields.

Despite the importance of the yield of long-term treasury bonds for macroeconomic outcomes, through its impact on the cost of borrowing, investment, or the prices of houses and other assets ${ }^{2}$ the understanding of its determinants is limited at best. For instance, while there has been a surge of papers that study the determinants of global imbalances and interest rates over this period $\square^{3}$ this literature, however, cannot account for the behavior of long-term yields, which became disconnected from short-term interest rates over a good part of this period 4

To disentangle the behavior of long-term yields, it is essential to understand the behavior of the risk compensation that agents demand for holding a risky asset -the term-premium:5 As argued by Bernanke (2006), distinguishing whether long-term yields are driven by higher expected yields or by a higher term-premium is key for understanding agents expectations about the behavior of macroeconomic variables and, thus, for the success of monetary policy. While high yields due to expectations of higher growth in the future -therefore, high future short-term interest rates-, prescribe contractionary measures, high long-term yields due to high term-premium -low future short-term interest rates- calls for the opposite approach. The term-premium in the U.S. has steadily declined over this period, as Figure 2 shows 6

1 Data from Treasury International Capital (TIC) system, U.S. Department of Treasury.

2 See, for example, Favilukis, Kohn, Ludvigson, and Van Nieuwerburgh (2012).

3 For example, Caballero, Farhi, and Gourinchas (2008), Caballero and Krishnamurthy (2009), Mendoza, Quadrini, and Rios-Rull (2009), among others.

4 See, for example, Greenspan (2005).

5 The difference between the long-term yield and the short-term interest rate can be decomposed into an expectations component - a weighted average of current and future interest rates- and the risk-premium —or term-premium.

6 The term-premium is unobservable and there are alternative ways to measure it. However, most available measures suggest a secular decline over this period (Swanson 2007), which led many to believe that the decline in the term- 
In order to understand the role of foreign purchases of U.S. Treasuries as a driver of the termpremium in the U.S., I set up a standard asset pricing model with three key ingredients: (i) external habit preferences; (ii) long-term debt; and (iii) non-zero foreign holdings of bonds of different maturities. These preferences have been shown to capture the size and time-variation of the risk-premium in the data, thus allowing the model to match several features of the real and nominal yield curves. Therefore, this framework has the potential to shed some light over the macroeconomic drivers of the decline in the term-premium and long-term yields.

Figure 1: 10-year zero-coupon US Treasury bond yields and foreign holdings of U.S. Treasuries

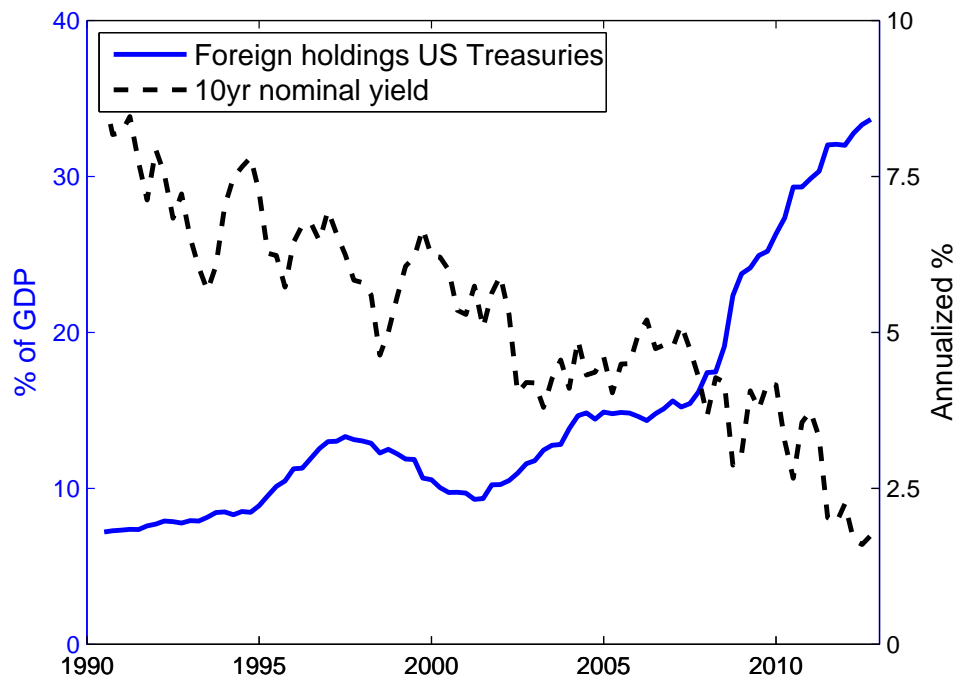

Notes: Data on nominal zero-coupon yields is from Gurkaynak, Sack, and Wright (2007), updated by Federal Reserve Board staff. Data on foreign holdings is from Treasury International Capital (TIC) system, U.S. Department of Treasury.

The model consists of an endowment economy inhabited by a domestic representative agent and foreign agents. The domestic agent maximizes expected utility and receives an stochastic endowment every period. The agent can also trade bonds of different maturities to smooth her intertemporal consumption profile. In particular, there are two types of bonds: a one-period bond and a perpetual long-term bond. This perpetuity pays a geometrically declining coupon that determines the duration of the bond 7 There is no default, so the real short-term bond is risk-less, while the long-term bond is subject to real risk depending on the cyclical behavior of interest rates. An exogenous stochastic process for inflation allows the pricing of nominal bonds.

premium was the explanation for the Greenspan's conundrum - See Kim and Wright (2005), Rudebusch, Swanson, and $\mathrm{Wu}$ (2006), Backus and Wright (2007).

7 As in Hatchondo and Martinez (2009), Arellano and Ramanarayanan (2012), Rudebusch and Swanson (2008). 
Figure 2: Term-premium for 10-year zero-coupon US Treasury bond

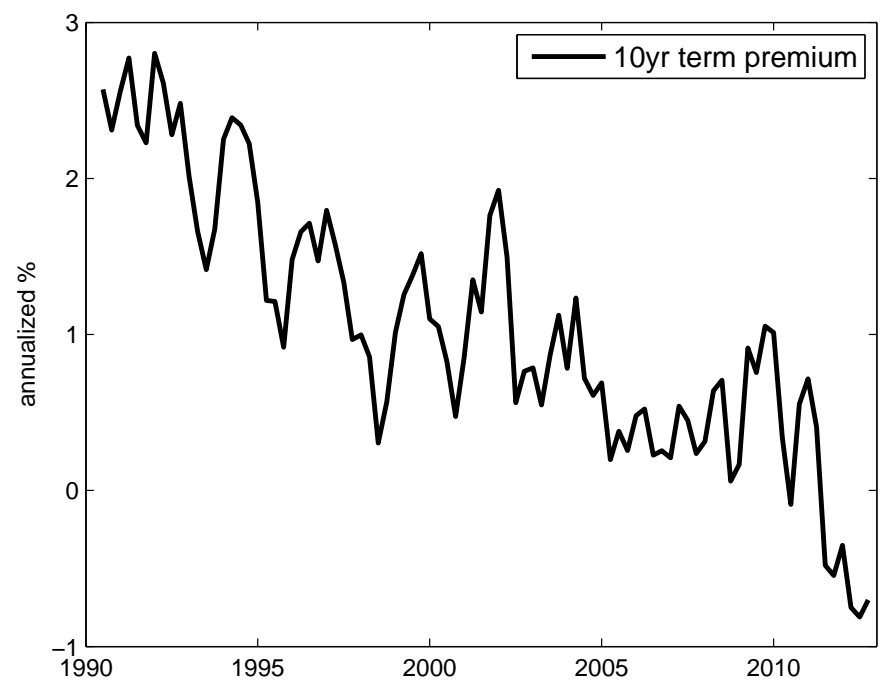

Notes: Data on the term-premium is from Kim and Wright (2005), updated by Federal Reserve Board staff.

Foreign agents purchase bonds, providing consumption goods in return. They are represented in the model by a stochastic demand for bonds, which I estimate from U.S. historical data jointly with endowment growth and inflation. As mentioned above, most of the recent increase in foreign holdings of U.S. Treasuries was driven by Foreign Official Institutions (FOI).$^{8}$ This is important, since it has been argued that the demand from these official institutions is fundamentally different from the private sector demand: FOI purchases are driven by a distinct set of incentives, namely reserve accumulation and foreign exchange intervention 9 implying that this demand is significantly more price-inelastic. Importantly, these institutions do not behave as private, portfolio-maximizers, agents. Therefore, I take an agnostic modeling approach and estimate these holdings directly from the data.

In order to study the quantitative implications of the model for bond prices and the termpremium, I assume that the domestic agent has external habits preferences, as studied by Campbell and Cochrane (1999) and Wachter (2006). These preferences imply that the agent values her consumption relative to a slow-moving reference level, which can be interpreted as a habit or as the aggregate consumption in the economy. This feature generates a countercyclical risk-aversion, which

\footnotetext{
8 Foreign Official Institutions are defined as primarily foreign national government institutions involved in the formulation of monetary policy, such as central banks, but also include national government owned investment funds. See TIC System, U.S. Department of Treasury.

9 See Alfaro, Kalemli-Ozcan, and Volosovych (2011), Donald Kohn (2002).
} 
allows the model to reproduce a large, positive, and countercyclical term-premium, as observed in the data. Long-term bonds are risky in the model because their prices are low in recessions, due to an increase in real interest rates 10

I use this model to investigate how much of the drop in long-term yields from 2000Q1 to 2007Q4 can be explained by foreign purchases ${ }^{11}$ and how much of this decline was due to changes in the term-premium. Since I study an endowment economy, I decompose observed consumption growth into two components: foreign purchases and the difference between observed consumption growth and foreign purchases. I am implicitly assuming that both consumption growth and foreign holdings observed in the data are equilibrium outcomes ${ }^{12}$ This approach is valid, as long as the process estimated from the data is an accurate description of the observed dynamics of consumption and foreign holdings. The goal of this exercise is to quantify the response of yields to the variation in consumption growth attributable to foreign purchases.

First, I show that the model delivers realistic implications for the yield curve. I estimate the stochastic process for the exogenous variables using U.S. data, and calibrate the preference parameters to match the average term structure of yields in the data. The model can match these features while generating realistic volatilities of interest rates. Then, I expose the domestic agent to the same path for the exogenous state variables observed during 2000Q1-2007Q4, and use the equilibrium policies, computed from the solution of the model, to study the simulated path of long-term yields and term-premium. I find that long-term yields in the model decrease by 1.2 percentage points, which accounts for 40 percent of the observed decline of yields in the data. The term-premium, which diminishes by 0.5 percentage points, explains 42 percent of the change in long-term yields.

To isolate the effect of foreign purchases during this period, I compare the yields implied by the model with the ones obtained under the assumption that foreign holdings stayed constant in terms of GDP at its level of 2000Q1 13 In this case, long-term bond yields increase by 3.16

\footnotetext{
${ }^{10}$ Below, I discuss why I chose this setup over an alternative model with recursive preferences and consumption growth stochastic volatility, that can also replicate some of these features.

${ }^{11}$ I exclude the financial crisis period, when various episodes of the European debt crisis triggered a flight to quality of private flows to U.S. Treasuries, and the Fed instrumented its Large Scale Asset Purchase program. These developments are not captured by this stylized model.

12 This assumption is common for consumption growth in asset pricing models with endowment economies. Favilukis, Ludvigson, and Van Nieuwerburgh (2012a) also take this approach for modeling foreign holdings.

13 That is, I assume a specific string of shocks to foreign holdings such that the stock of holdings over GDP stays constant.
} 
percentage points, and the term-premium by 1.02 percentage points. These results suggest that foreign purchases decreased long-term yields by 4.37 percentage points, the difference between the change in yields with constant foreign holdings and the change in yields when the path of foreign holdings was the one observed in the data. The term-premium explains one-third of this decline. However, foreign purchases increase the yield slope. This is because they decrease short-term rates by more than future expected short-term yields, which offsets the drop in the term-premium.

Foreign purchases affect bond yields in this model by affecting expected consumption growth and consumption growth innovations. On the one hand, foreign purchases increase current consumption and reduce expected consumption growth, since next-period's consumption is expected to be lower when debt needs to be repaid. This induces agents to save, so short-term interest rates need to decrease to restore the equilibrium in the bond market. On the other hand, agents are surprised every period by higher-than-expected consumption growth. This is because new and unexpected foreign purchases of U.S. Treasuries raise consumption growth above its expected value, which increases surplus consumption - the difference between current consumption and a weighted average of past consumption or habit. Higher surplus consumption in the model decreases risk-aversion, leading agents to request a lower term-premium.

Finally, I investigate the effect of a reversal of foreign inflows of U.S. Treasury debt. Discussion about the sustainability of global imbalances has led to speculation over the possible consequences of a sell-off of U.S. debt by foreign governments. I use my model to provide an estimate of the effects of this sell-off on U.S. Treasury yields and bonds term-premium. I assume that China and Japan, the two largest foreign holders of U.S. Treasuries with 46 percent of the total foreign holdings, decide to stop rolling over their Treasuries. I use data on the maturity structure of foreign official institutions' holdings to determine the speed of this adjustment. Beginning in June 2013, foreign holdings decline from 23.8 percent of GDP to 13 percent of GDP over the following ten years, with almost half of that adjustment occurring in the first three years. My results suggest that long-term bond yields would increase by 5 percentage points during the first three years, of which 2.1 percentage points are explained by an increase in the term-premium.

My findings suggest that time-varying risk premia played a significant role in the recent dynamics of long-term interest rates. In this model, long-term bonds are risky because of countercyclical short-term real interest rates, that cause bond prices to covary positively with consumption growth. 
There is an additional risk-premium in nominal bonds, due to the negative covariance between consumption growth and inflation, but it plays a minor role in the dynamics of the term-premium, which is mostly driven by the real risk-premium. This is in contrast to another potential explanation of time-variation in risk premium, namely that a reduction in inflation uncertainty has caused a drop in the term-premium, particularly during the 1990s 14 This hypothesis is downplayed by evidence on the U.S. TIPS markets, however, since inflation uncertainty does not affect the yields of inflation-indexed bonds and these behaved similarly to nominal bond yields for the period of analysis 15

In the rest of this section, I discuss the related literature. In Section 2, I introduce the model. In Section 3, I present and discuss the main results from the simulations. At the end of that section, I study the case of a reversal in foreign flows. Finally, the conclusions are presented in Section 4.

\subsection{Related Literature}

This paper is related to recent papers that have studied the determinants of the global imbalances, the excess supply of savings, and the behavior of the interest rates for safe assets, as in Caballero (2006), Caballero, Farhi, and Gourinchas (2008), Caballero and Krishnamurthy (2009), and Mendoza, Quadrini, and Rios-Rull (2009) ${ }^{16}$

In contrast to the papers above, I investigate the effect of these flows on long-term yields, the shape of the term-structure of interest rates, and the term-premium. Since Fama and Bliss (1987) and Campbell and Shiller (1991), there is cumulative evidence that risk-premia are time-varying and countercyclical 17 and this feature is needed to capture the upward sloping shape of the yield curve observed in the data. ${ }^{18}$ Furthermore, there is wide consensus that this premium has been declining over the last two decades ${ }^{19}$ However, despite the recent progress relating movements in yields and the term-premium with macroeconomic variables, we are still missing a good understanding of the

\footnotetext{
${ }^{14}$ See, for example, Piazzesi and Schneider (2006) and Bansal and Shaliastovich (2012).

${ }^{15}$ Piazzesi and Schneider (2006) predicts a flat real yield curve, while the mechanism in Bansal and Shaliastovich (2012) implies a negatively sloped real yield curve, due to flight to quality in recessions. In U.S. data, however, the real yield curve typically slopes up. Furthermore, TIPS yields have moved almost in tandem with nominal yields. See Gurkaynak and Wright (2012).

${ }^{16}$ Another related strand of literature has focused on documenting the puzzling behavior of capital flows, which flowed from developing countries - mostly Asian countries- to developed economies, as in Lucas (1990), Gourinchas and Jeanne (2013), and Alfaro, Kalemli-Ozcan, and Volosovych (2014). For alternative explanations for the global imbalances, see Angeletos and Panousi (2011), Aguiar and Amador (2011), and Maggiori (2013).

${ }^{17}$ See, for example, Ludvigson and Ng (2009), Cochrane and Piazzesi (2005), and Cochrane and Piazzesi (2008).

${ }^{18}$ See Backus, Gregory, and Zin (1989).

${ }^{19}$ See Rudebusch, Sack, and Swanson (2007)
} 
macroeconomic forces driving the bond term-premium 20

Related to my findings, there is a large body of empirical evidence that documents the effects of foreign purchases of U.S. Treasuries on yields and bonds term-premia. Bernanke, Reinhart, and Sack (2004) finds that Japanese daily interventions on the foreign exchange market decrease U.S. Treasury 10-year yields, during the period 2000 to 2004. Warnock and Warnock (2009) further suggests that foreign purchases flatten the yield curve with large effects on 10-year yields but not on 2-year yields, for 1984 to 2005. On the same line, Beltran, Kretchmer, Marquez, and Thomas (2013) results show that an inflow of $\$ 100$ billion USD reduces the 5-year premium by 0.46 to 0.50 percentage points. Focusing on forecasting realized excess returns instead, Sierra, Jesus (????) finds that official flows have a negative and non-linear effect similar to supply shocks 21

These papers point towards a negative correlation between foreign purchases and long-term yields, or between foreign purchases and the term-premium. However, they are silent regarding the mechanism behind these effects. I quantify these effects in a consumption-based model where bond prices and the term-premium are equilibrium outcomes, and show how they are affected by foreign purchases of U.S. Treasuries.

A related explanation relies on segmented markets for bonds of different maturities. Under this setup, the desire of foreigners for bonds of long-maturities induced a fall in long-term yields and the term-premium. Kaminska and Zinna (2014) build and estimate a structural arbitrage-free model with these characteristics, and estimate that foreign purchases of U.S. Treasuries cumulatively reduced long-term real yields by 80 basis points by $2008{ }^{22}$ While this is an intuitive argument, it is hard to reconcile with the evidence that the average maturity of foreign holdings was close to four years, while the effects of these purchases affected longer-term yields.

With a quantitative approach closer to the one in this paper, Justiniano, Primiceri, and Tambalotti (2013) use a medium scale DSGE model to study the effects of both the saving glut and banking glut on interest rates and house prices. Their model, however, is silent regarding the risk premium and long-term yields, which are the focus of my paper. Favilukis, Ludvigson, and Van Nieuwerburgh (2012a) provides an alternative framework ${ }^{23}$ to study the effects of foreign inflows to

\footnotetext{
${ }^{20}$ See Gurkaynak and Wright (2012) for a survey on this literature. Rudebusch and Swanson (2008), Rudebusch and Swanson (2012) for some recent examples.

${ }^{21}$ See also Bertaut, DeMarco, Kamin, and Tryon (2011) and Bernanke, Bertaut, DeMarco, and Kamin (2011).

${ }^{22}$ A similar model is used by Vayanos and Vila (2009), Kaminska, Vayanos, and Zinna (2011), and Hanson and Stein (2014) to study the U.S. term structure of real rates and the long-run real effects of monetary policy.

23 This is the same framework than in Favilukis, Ludvigson, and Van Nieuwerburgh (2012b).
} 
safe assets on welfare. They model foreign holdings of safe assets as following an exogenous process like I do, but in a setup with production and heterogenous agents. However, they don't look at the term structure of interest rates and bonds term-premium, as I do.

The model in my paper extends Wachter (2006) to allow for foreign holdings of bonds of different maturities. As such, it also draws on the earlier literature on habit formation ${ }^{24}$ In her model, however, nominal zero-coupon bonds are in zero-net supply, and consumption is parametrized as a random walk. In this paper foreign purchases introduce a predictable component in consumption growth. Furthermore, bond prices depend on current and past foreign holdings, which makes the model challenging to solve numerically.

\section{The Model}

In this Section, I introduce the model to study the effect of foreign purchases of U.S. Treasuries on long-term bond yields and the term-premium. In the following section, I solve this model numerically, and I use it to investigate the quantitative impact of foreign purchases in the U.S. and the counterfactual effect of a reversal of foreign capital inflows.

As I will discuss below, a model with habit preferences can capture several features of the bonds yield curve in the data. In particular, it can generate a positive and sizable term-premium, which is necessary to replicate an upward average yield curve as in the data.25 At the same time, it reproduces a realistic volatility of interest rates ${ }^{26}$ because it breaks the link between the intertemporal elasticity of substitution and the relative risk aversion, implied by standard isoelastic preferences. Finally, and directly related to the focus of this paper, it generates a time-varying term-premium 27

${ }^{24}$ Among these: Campbell and Cochrane (1999), Abel (1990), Constantinides (1990), Ferson and Constantinides (1991), Heaton (1995) and Sundaresan (1989).

${ }^{25}$ For example, Backus, Gregory, and Zin (1989) shows that an endowment economy with complete markets and standard CRRA preferences can account for neither the sign nor the magnitude of average risk premia.

${ }^{26}$ The difficulty in generating both realistic risk premium and interest rates volatility is known as risk-free rate puzzle, see Weil (1989).

${ }^{27}$ See Wachter (2006). Campbell and Cochrane (1999) is a similar setup, but with a constant risk-free rate. 
The preferences of the domestic agent depend on an external habit, or subsistence level $X_{t}$ :

$$
\begin{aligned}
u\left(C_{t}, X_{t}\right) & =\frac{\left(C_{t}-X_{t}\right)^{1-\gamma}-1}{1-\gamma} \\
& =\frac{\left(C_{t} S_{t}\right)^{1-\gamma}-1}{1-\gamma}
\end{aligned}
$$

where $S_{t} \equiv \frac{C_{t}-X_{t}}{C_{t}}$ is surplus consumption.

The habit $X_{t}$ is external, which implies that the agent does not consider the effect of its decisions on the future level of the habit when deciding its optimal consumption choice. These preferences are characterized by time-varying relative risk aversion:

$$
-\frac{u^{\prime \prime}\left(C_{t}, X_{t}\right) C_{t}}{u^{\prime}\left(C_{t}, X_{t}\right)}=\frac{\gamma}{S_{t}}
$$

Risk aversion varies with surplus consumption, which is procyclical: risk aversion is higher in bad times commanding a higher risk premium, and declines during expansions. This is the force driving time-variation in the term-premium in the model.

Notice also that this model can generate a high average value of risk aversion for a small value of the utility curvature parameter, $\gamma 28$ This allows the intertemporal elasticity of substitution to have a value consistent with a realistic volatility of interest rates.

The process for log surplus consumption is

$$
s_{t+1}=(1-\phi) \bar{s}+\phi s_{t}+\lambda\left(s_{t}\right)\left(\Delta c_{t+1}-E_{t} \Delta c_{t+1}\right)
$$

where a high value for $\phi$ implies a slow-moving habit.

The specification of the surplus consumption process in logs ensures that consumption never falls below the habit. Furthermore, this process is heteroskedastic given that $\lambda$ varies over time, and positively correlated with consumption growth innovations.

The sensitivity of log surplus consumption to consumption growth innovations, $\lambda\left(s_{t}\right)$, is defined as in Wachter (2006):

\footnotetext{
${ }^{28}$ In time-additive, isoelastic expected utility, the intertemporal elasticity of substitution is given by $1 / \gamma$, the inverse of the constant relative risk aversion coefficient.
} 


$$
\begin{aligned}
\lambda\left(s_{t}\right) & =\left\{\begin{array}{cc}
\frac{1}{\bar{S}} \sqrt{1-2\left(s_{t}-\bar{s}\right)}-1 & \text { if } s_{t} \leq s_{\max } \\
0 & \text { if } s_{t}>s_{\max }
\end{array}\right. \\
s_{\max } & =\bar{s}+\frac{1}{2}\left(1-\bar{S}^{2}\right) \\
\bar{S} & =\sigma_{c} \sqrt{\frac{\gamma}{1-\phi-b / \gamma}}
\end{aligned}
$$

where $\sigma_{c} \equiv S t d_{t}\left(\Delta c_{t+1}-E_{t}\left[\Delta c_{t+1}\right]\right)$ is the conditional standard deviation of consumption growth innovations.

This function, $\lambda\left(s_{t}\right)$, is specifically designed to capture several important features of the habit process 29 In particular, when surplus consumption equals its long-run value $\bar{s}$, the habit is a function of past consumption. Moreover, the risk-free rate depends on surplus consumption, with the sign of the relationship depending on the sign of $b 30$

Every period the domestic agent receives a stochastic endowment $Y_{t}$, and has access to two types of assets: one-period bonds and long-term bonds. I model long-term bonds as perpetuities that pay geometrically declining coupons, as in Arellano and Ramanarayanan (2012) and others. ${ }^{31}$

The lender of these nominal long-term bonds gives $q_{t}^{L} L_{t}$ units of currency in period $\mathrm{t}$ and receives $\delta^{n-1} L_{t}$ units of currency in every period $t+n$. Then, defining $B_{t}^{L}$ as the stock of long-term bonds at time $t$, or the total payments due in period $t$ on all past issuances,

$$
B_{t}^{L}=\sum_{j=0}^{t} \delta^{j} L_{t-j}=L_{t}+\delta L_{t-1}+\ldots+\delta^{t} L_{0}+B_{0}^{L}
$$

where $B_{0}^{L}$ is given.

Notice that the law of motion for $B_{t}^{L}$ can be written recursively as:

$$
B_{t}^{L}=\delta B_{t-1}^{L}+L_{t}
$$

This formulation alleviates the need for additional state variables which would be necessary in the case of zero-coupon, long maturity, bonds. Furthermore $\delta$ can be calibrated to match the

\footnotetext{
${ }^{29}$ See Campbell and Cochrane (1999) for more details on this.

${ }^{30}$ When consumption is a random walk, Wachter (2006) shows that the risk-free rate depends linearly on surplus consumption.

${ }^{31}$ See also Hatchondo and Martinez (2009) and Rudebusch and Swanson (2008).
} 
duration of long-term zero-coupon bonds, which makes this perpetuity an attractive substitute for modeling purposes.

Foreign agents are described by a stochastic demand for bonds, following a process which I estimate from U.S. data. This choice responds to the concerns expressed above, that Foreign Official Institutions have an objective function guided by different incentives than private investors solving a standard portfolio choice problem. Therefore, I take an agnostic view of the preferences guiding this process, and instead estimate this foreign demand from the data.

Furthermore, I assume that every period foreign agents hold a fixed fraction of their total stock of bonds in short-term bonds. Then, their portfolio decision is given by $\alpha$, the share of short-term bond purchases, which will be calibrated to match the average share of short-term foreign holdings in the data. While this assumption is not necessary, it simplifies the problem since it avoids having to keep track of both long- and short- term foreign holdings. Instead, both are driven by the total foreign holdings $F_{t}$ :

$$
\begin{aligned}
& F_{t}^{S}=\alpha F_{t} \\
& F_{t}^{L}=(1-\alpha) F_{t}
\end{aligned}
$$

Equation 7 presents the problem that the domestic agent in this economy needs to solve every period:

$$
\begin{aligned}
& \max _{C_{t}, B_{t}^{S}, B_{t}^{L}, L_{t}} E_{0}\left(\sum_{t=0}^{\infty} \beta^{t} \frac{\left(C_{t} S_{t}\right)^{1-\gamma}-1}{1-\gamma}\right) \\
& \text { s.t. } \\
& C_{t}+q_{t}^{S} \frac{B_{t}^{S}}{P_{t}}+q_{t}^{L} \frac{L_{t}}{P_{t}}= Y_{t}+\frac{B_{t-1}^{S}}{P_{t-1}} \frac{P_{t-1}}{P_{t}}+\frac{B_{t-1}^{L}}{P_{t-1}} \frac{P_{t-1}}{P_{t}} \\
& B_{t}^{L}= \delta B_{t-1}^{L}+L_{t} \\
& s_{t+1}=(1-\phi) \bar{s}+\phi s_{t}+\lambda\left(s_{t}\right)\left(\Delta c_{t+1}-E_{t} \Delta c_{t+1}\right) \\
& \frac{B_{t}^{S}}{P_{t}}+\frac{B_{t}^{L}}{P_{t}}\left(1+\delta q_{t}^{L}\right) \geq \widetilde{b}_{t}
\end{aligned}
$$

where $\widetilde{b}_{t}$ is the natural debt limit. 
The market clearing conditions for bonds are given by,

$$
\begin{aligned}
& B_{t}^{S}+F_{t}^{s}=0 \\
& B_{t}^{L}+F_{t}^{L}=0
\end{aligned}
$$

To complete the model, I assume that endowment growth, $\Delta y_{t} \equiv \log \left(\frac{Y_{t}}{Y_{t-1}}\right)$, real foreign holdings over the endowment, $f_{t} \equiv \frac{F_{t}}{P_{t} Y_{t}}$, and inflation, $\pi_{t} \equiv \log \left(\frac{P_{t}}{P_{t-1}}\right)$, follow a VAR $(1)$ process.

$$
\begin{aligned}
& X_{t}=(I-A) \mu+A X_{t-1}+\epsilon_{t} \\
& X_{t} \equiv\left(\begin{array}{c}
\Delta y_{t} \\
f_{t} \\
\pi_{t}
\end{array}\right), \epsilon_{t} \equiv\left(\begin{array}{c}
\epsilon_{\Delta y, t} \\
\epsilon_{f, t} \\
\epsilon_{\pi, t}
\end{array}\right)
\end{aligned}
$$

where $A$ is a $3 x 3$ matrix and $\epsilon_{t} \sim N(0, \Sigma)$, with $\Sigma$ also a $3 x 3$ matrix.

This parsimonious specification with only one lag helps keeping the model tractable.

Notice that, while quantities in the model are exogenous, bond prices are endogenous and adjust in order to clear the markets. In the following subsection, I solve for the expressions that characterize the dynamics of bond prices in this economy and show how they are affected by foreign purchases.

\subsection{Equilibrium bond prices}

In this subsection I obtain the expressions that characterize the equilibrium policies for bond prices and consumption. Since I cannot get closed form solutions for bond prices, in the next section I solve for these numerically.

Definition Let endowment growth, foreign holdings, and inflation follow the process in Equation 9 let holdings of short-term bonds be given by $\alpha$. An equilibrium in this economy is a sequence of consumption choices and bond holdings, $\left\{C_{t}, B_{t}^{S}, B_{t}^{L}\right\}_{t=0}^{\infty}$, and bond prices, $\left\{q_{t}^{S}, q_{t}^{L}\right\}_{t=0}^{\infty}$, such that:

1. Given bond prices and the process for endowment growth, foreign holdings and inflation, the agent chooses consumption and bond holdings to solve the problem given in Equation 7. 
2. Markets for short- and long-term bonds clear (Equation 8).

The first order conditions (FOC) of the domestic agent's problem (Equation 7) are:

$$
\begin{aligned}
q_{t}^{S} & =E_{t}\left[M_{t+1}^{\$}\right] \\
q_{t}^{L} & =E_{t}\left[M_{t+1}^{\$}\left(1+\delta q_{t+1}^{L}\right)\right]
\end{aligned}
$$

where $M_{t+1}^{\$}=\beta\left[\left(\frac{C_{t+1}}{C_{t}} \frac{S_{t+1}}{S_{t}}\right)^{-\gamma} \frac{P_{t}}{P_{t+1}}\right]$

Using the market clearing conditions for bonds Equation 8) and the budget constraint of the agent,

$$
c_{t}=1+\left(\alpha q_{t}^{S}+(1-\alpha) q_{t}^{L}\right) f_{t}-\left(1+(1-\alpha) \delta q_{t}^{L}\right) f_{t-1} \frac{Y_{t-1}}{Y_{t}} \frac{P_{t-1}}{P_{t}}
$$

where $c \equiv \frac{C}{Y}$.

Consumption depends both on the endowment, and the current account deficit, which mirrors the foreign purchases of bonds in this economy. Therefore, while trading bonds, foreigners will effectively be financing consumption and affecting the consumption growth process and bond prices. Also, the current account deficit depends not only on the quantity of bond purchases, but on its price: for any given demand of bonds, a higher price will allow higher consumption.

Finally, notice that a higher stock of debt at $t-1$ diminishes consumption at $t$, since it means higher debt payments at $t$, and its magnitude depends on the price of long-term debt, endowment growth from $t-1$ to $t$, and inflation from $t-1$ to $t$. Due to the existence of long-term debt, a higher price of debt means higher debt payments; this feature of the model will potentially capture some of the valuation effects that have been quantitatively important over the recent period in the U.S ${ }^{32}$ On the other hand, inflation can dilute the value of debt since these are nominal bonds. Endowment growth also appears in this equation since the stock of debt is normalized by the endowment.

Bond prices are functions of 5 state variables in this problem: $q\left(s_{t}, \Delta y_{t}, f_{t}, f_{t-1}, \pi_{t}\right)$, where $s_{t}$ is $\log$ surplus consumption, $\Delta y_{t}$ is endowment growth, $f_{t}$ is the foreign bond holdings over the endowment at $t$ and $f_{t-1}$ is the one corresponding to the previous period, and $\pi_{t}$ is the consumption

\footnotetext{
${ }^{32}$ See Gourinchas and Rey (2013).
} 
good price growth. In the next section, I solve for these prices numerically, given the exogenous process in Equation 9 above.

\section{Quantitative Results}

In this section, I present the results from the model introduced above. I estimate the process for endowment growth, foreign holdings and inflation from U.S. data, for 1952Q1-2006Q4, and calibrate the preference parameters to match the average level of yields over this period. Then, I use the model to ask how much of the large drop observed in long-term yields during the 2000s, as shown in Figure 1 above, can be explained by the dramatic increase in foreign purchases of U.S. Treasuries by Foreign Official Institutions, and how much of this change is attributable to risk compensation. In the following subsection, I provide an explanation of the mechanism driving these effects. The section concludes with a counterfactual exercise that studies the response of yields and the term-premium to a reversal of foreign purchases of U.S. treasuries.

\subsection{Calibration}

I estimate the exogenous process for $\Delta y_{t}, \pi_{t}, f_{t}$ in Equation 9 for the period 1952Q1-2006Q4. Since this is an endowment economy, the common practice in asset pricing models is to estimate endowment growth with consumption growth data. However, in this model consumption growth depends on endowment growth and on the change in foreign purchases normalized by the level of the endowment, which in the model is equivalent to the change in the current account deficit over the endowment.

$$
\begin{aligned}
\Delta \log C_{t} & \approx \Delta \log Y_{t}+\Delta \frac{C A d e f_{t}}{P_{t} Y_{t}} \\
& \Rightarrow \Delta y_{t} \approx \Delta \log C_{t}-\Delta \frac{C A d e f_{t}}{P_{t} Y_{t}}
\end{aligned}
$$

Therefore, as a proxy for $\Delta y_{t}$, I use data on growth of real consumption of nondurables and services, per-capita, minus the change in trade balance deficit over GDP ${ }^{33}$ Data on consumption and trade balance is from BEA. Inflation, $\pi_{t}$, is U.S. CPI growth data, from BLS.

Finally, $f_{t}$ is the stock of U.S. Treasuries by Foreign Official Institutions over nominal trend

\footnotetext{
${ }^{33}$ I use data on trade balance instead of current account balance, since this series goes back to 1952.
} 
GDP. Data on U.S. Treasuries holdings by FOI includes Treasury bills, bonds and notes and is taken from the Flow of Funds, release Z.1, published by the Federal Reserve. These data are based on the Treasury International Capital (TIC) reporting system and are adjusted by BEA to account for systematic and known under- or overestimating of reported transactions, based largely on the annual surveys, and for valuation adjustments. The Appendix provides additional details on the data sources. Foreign holdings are normalized by trend nominal GDP 34

The choice of the estimation period for 1952Q1 to 2006Q4 is dictated by the availability of data since 1952Q1, and because the main exercise excludes the financial crisis, for reasons explained below. The estimated process is 35

$$
\begin{gathered}
A=\left(\begin{array}{ccc}
0.1329 & -0.0659 & -0.0811 \\
-0.0247 & 0.9944 & 0.0062 \\
0.2080 & 0.0472 & 0.8667
\end{array}\right) \\
(I-A) \mu=\left(\begin{array}{llll}
0.0054 & 0.0001 & -0.0002
\end{array}\right)^{\prime} \\
\Sigma=1.0 e-004 x\left(\begin{array}{ccc}
0.2450 & 0.0030 & -0.0498 \\
0.0030 & 0.0011 & -0.0077 \\
-0.0498 & -0.0077 & 0.1601
\end{array}\right)
\end{gathered}
$$

Given this process, I simulate the model and calibrate the preference parameters. A period in my model is one quarter. There are four preference parameters: the utility curvature, $\gamma$, the subjective discount factor, $\beta$, the persistence of the log surplus consumption, $\phi$, and a parameter that affects the sensitivity of the log surplus consumption to consumption growth shocks in Equation 4, $b$. As explained below, a large and positive $b$ drives a large and positive risk-premium, since it commands a countercyclical risk-free rate. I choose $\beta$ and $b$ to match two targets: the level and slope of the average yield curve. I fix $\phi=0.97$ as in Campbell and Cochrane (1999) ${ }^{36}$ The inverse of the elasticity of intertemporal substitution drives the sensitivity of the real interest rate to expected

\footnotetext{
${ }^{34}$ I use Hodrick-Prescott filter with smoothing factor of 1600 . The choice of dividing by the trend instead of the actual series of GDP is done so that the series does not reflect strong variations attributable only to the upward and downward swings of GDP during the business cycle.

${ }^{35}$ For more details on the estimation, see the Appendix.

36 They show that this value matches the first order autocorrelation of the price-dividend ratio.
} 
consumption growth; since in this model expected consumption growth is very volatile due to foreign purchases, I set $\gamma=1$ to keep interest rates volatility realistic 37 Table 1 presents the results of the calibration exercise 38

Table 1: Preference parameters, quarterly

\begin{tabular}{ccll}
\hline$\beta$ & 0.99 & Discount rate & $E\left(y_{t}^{s}\right)$ \\
$b$ & 0.015 & $y_{t}^{s}$ countercyclical & $E\left(y_{t}^{L}\right)$ \\
$\phi$ & 0.97 & Habit persistence & Campbell and Cochrane (1999) \\
$\gamma$ & 1 & Utility curvature & $?$ \\
\hline
\end{tabular}

Finally, the rate of geometric decline of the long-term bond coupons, $\delta$, is set so that the duration of the perpetuity is 16 quarters, the weighted average maturity of foreign holdings of U.S. Treasury holdings by Foreign Official Institutions at June of 2013. This implies $\delta=0.947$. More details on this calculation can be found in the Appendix 39 The share of short-term foreign purchases, $\alpha$, is chosen to match the average share of short-term treasuries (Treasury bills) held by foreigners during 1994-2006 40

Table 2: Long-term bonds

\begin{tabular}{lcl}
\hline$\delta$ & 0.947 & Match maturity of 16 quarters; \\
$\alpha$ & 0.18 & Mean share short-term Treasuries holdings by foreigners \\
\hline
\end{tabular}

Scaling foreign holdings. I use a perpetuity to model long-term bonds, whereas in the data this type of perpetuity bonds is rare. While I calibrate the rate of decline of the coupons to match the average maturity of these bonds, there is a significant difference regarding their present value. ${ }^{41}$ Therefore, I scale down foreign holdings by a constant factor, to equalize their present values.

In the data, the value of long-term foreign holdings is given by $q_{t}^{(16)} F_{t}^{(16)}$, where $q_{t}^{(16)}$ is the price of a 16-quarter bond at $t 42$ To equalize their present value with the present value of a long-term 37 This a standard value in the macro literature, see ?.

${ }^{38}$ Numerically I obtain that, around the parameters chosen, an increase in b increases the level and the slope while an increase in $\phi$ reduces the slope but increases the level. Finally, an increase in $\beta$ decreases mean yields but increases the slope.

${ }^{39}$ I use an average quarterly yield of 1 pp to discount the bonds.

${ }^{40}$ This fraction has been decreasing over time, but has fluctuated around $18 \%$ for the last two decades. I choose to match this value. This fraction is currently around $9 \%$.

${ }^{41}$ i.e., a zero-coupon bond of 4 years, discounted by an quarterly average yield of $1 \%$ has a price of $e^{-0.01 x 16} \approx 0.85$, while a consol has a price of $16 e^{-0.01} \approx 15.84$

${ }^{42} \mathrm{I}$ am assuming these bonds are zero-coupon as an approximation. 
bond in the model, $q_{t}^{L} F_{t}^{L}$, long-term flows need to be adjusted:

$$
F_{t}^{L}=\frac{q_{t}^{(16)}}{q_{t}^{L}} F_{t}^{(16)}, q_{t}^{L}=\frac{e^{-y_{t}}}{1-\delta e^{-y_{t}}}, q_{t}^{(16)}=e^{-y_{t} 16}
$$

where $y_{t}$ is the quarterly yield to maturity observed in the data. To avoid further distortions to the data, I restrict myself to a constant adjustment, and use instead $\frac{q^{(16)}}{q^{L}}$, where both prices are obtained using a constant average yield of 1pp, quarterly.

To keep short-term foreign purchases as in the data, $\alpha$ needs to be adjusted consistently. Define $K=\alpha+(1-\alpha) \frac{q^{(16)}}{q^{L}}$, then the adjusted share of short-term holdings and adjusted flows are:

$$
\widetilde{\alpha}=\frac{\alpha}{K}, \widetilde{F}_{t}=K F_{t}
$$

Given the calibration above, $\frac{q^{(16)}}{q^{L}}=0.0538, K=0.224$ and $\widetilde{\alpha}=0.80$.

Solution. As discussed above, bond prices need to be solved numerically. I discretize the continuous process using a code by Knotek II and Terry (2010), which is an extension of Tauchen (1986) that allows for a nondiagonal covariance matrix. Given the number of state variables in my problem, the grid size for each variable is necessarily small. I use a grid of 11 carefully chosen values for surplus consumption 43 equidistant values for income growth, 45 equidistant values for stock of foreign debt, both at $t$ and $t-1$, and 5 equidistant values for inflation. Bond prices are solved for each grid point and then these prices are linearly interpolated when I simulate the economy for 440,000 quarters, burning the first 40,000 observations. In the remaining of this subsection, I show that this model can match the level and slope of the average yield curve in U.S. data.

I focus the analysis on bond yields, which are related to bond prices as follows:

$$
y_{t}^{S}=\log \left(\frac{1}{q_{t}^{S}}\right), y_{t}^{L}=\log \left(\frac{1+\delta q_{t}^{L}}{q_{t}^{L}}\right)
$$

The long-term yield for the perpetuity in the model, derived above, reflects the fact that a unit of this asset at $t$ is a claim to a unit of consumption plus a unit of the bond at $t+1$, with the latter discounted by $\delta 44$

\footnotetext{
$\overline{43}$ The grid points are carefully chosen so that the model without foreign purchases replicates closely the results in Wachter (2006).

${ }^{44}$ The data is for a yield on a zero-coupon, 16 quarters, bond. Its quarterly yield is given by $y_{t}^{(16)}=-\frac{1}{16} \log \left(q_{t}^{(16)}\right)$
} 
Table 3 presents the average yields in the simulation, and their standard deviation, for both real and nominal yields, and compares them with the data.

Table 3: Bond Yields, simulation results and data

\begin{tabular}{cccc} 
& \multicolumn{2}{c}{ Model } & Data \\
& Real & Nominal & Nominal \\
$E\left(y_{t}^{S}\right)$ & 1.27 & 5.14 & 5.14 \\
$E\left(y_{t}^{L}\right)$ & 2.41 & 6.01 & 6.04 \\
$E\left(y_{t}^{L}-y_{t}^{S}\right)$ & 1.14 & 0.87 & 0.90 \\
\hline$\sigma\left(y_{t}^{S}\right)$ & 2.54 & 3.83 & 2.89 \\
$\sigma\left(y_{t}^{L}\right)$ & 2.49 & 2.62 & 2.77 \\
$\sigma\left(y_{t}^{L}-y_{t}^{S}\right)$ & 0.57 & 1.90 & 0.94
\end{tabular}

Notes: numbers in the table are moments for long-run simulation of the Model, and sample moments for 1952Q1-2006Q4 for the Data. In the data column, $y_{t}^{S}$ is the $3 \mathrm{~m}$ yield, and $y_{t}^{L}$ is the $4 \mathrm{yr}$ zero-coupon bond yield, from Fama-Bliss dataset.

As explained above, the preference parameters $(\beta$ and $b)$ are calibrated to target the average short-term and long-term yields, and the model can match them almost perfectly. Moreover, the model does a good job regarding the volatilities. As in the data, short-term yields are more volatile than long-term yields. On the one hand, expected consumption growth is very volatile, due to foreign purchases, and this affects primarily short-term real rates. On the other hand, expected inflation affects short-term yields more than long-term yields. This is the reason behind the nominal short-term rate being much more volatile than in the data. ${ }^{45}$

\subsection{The "savings glut" period}

In the previous subsection, I showed that this model can match the main features of the average yield curve in the data. In this subsection, I use the model to study the extent to which foreign purchases contributed to the decline in long-term yields, both nominal and real, observed during the period 2000Q1-2007Q4. Since the model can generate time-varying risk premium, I quantify the contribution of the term-premium to the drop in long-term yields over this period, and study the effects of foreign purchases on the term-premium. To do this, I use the model as a laboratory: I expose the agent in the model to the shocks observed in U.S. during this period, and use the solution of the model to compute the equilibrium consumption and bond prices in response to

\footnotetext{
45 This is in part caused by the small grid chosen for inflation in the discretization, since in the simulation inflation has a standard deviation of $1.03 \%$ higher than its sample counterpart in the data, $0.75 \%$. Notice also that this is a nominal phenomenon since real short-term rates are not that much more volatile than the long-term real yields.
} 
these shocks. During this period, agents' perceived law of motion for the exogenous process is the one I estimated from the data above 46

I focus on the period going from 2000 to 2007, which Bernanke (2005) and others have characterized as undergoing a "savings glut" in the world: a situation in which there were worldwide excess of savings, mainly from Asian countries, with respect to investment opportunities. I exclude the financial crisis period, characterized by various episodes of flight to quality of private flows to U.S. treasuries, liquidity shocks, and also by the large asset purchases by the Fed. My model is not designed to capture these developments.

For ease of exposition, I first smooth $\Delta y, \pi$, and $f$, by taking 4-quarter moving averages. Figure 3 shows the paths for the (smoothed) exogenous state variables in the data.

Figure 3: Exogenous state variables
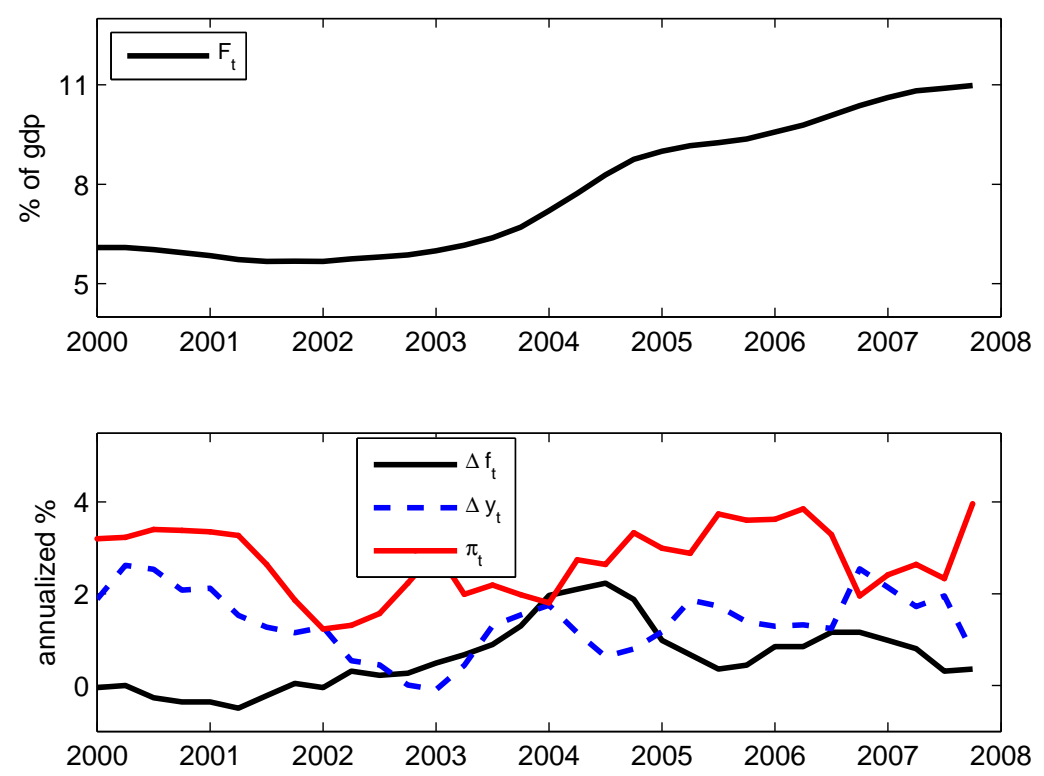

Figure 4 presents the simulated paths for the nominal yields and the yield slope for the model (black lines with squares) and the counterparts in the data (blue dashed lines). The data on yields is for a 4-year zero-coupon Treasury bond and 3-month Treasury-based risk-free rate.

Long-term yields implied by the model are close to their data counterparts at the beginning and end of the sample. However, the model fit misses the data during 2002-2004, with both short- and ${ }^{46}$ Under the lens of the model, the increase in foreign holdings observed during this period was a particular string of
transitory shocks. 
Figure 4: Nominal yields and yield curve slope

Long-term yields
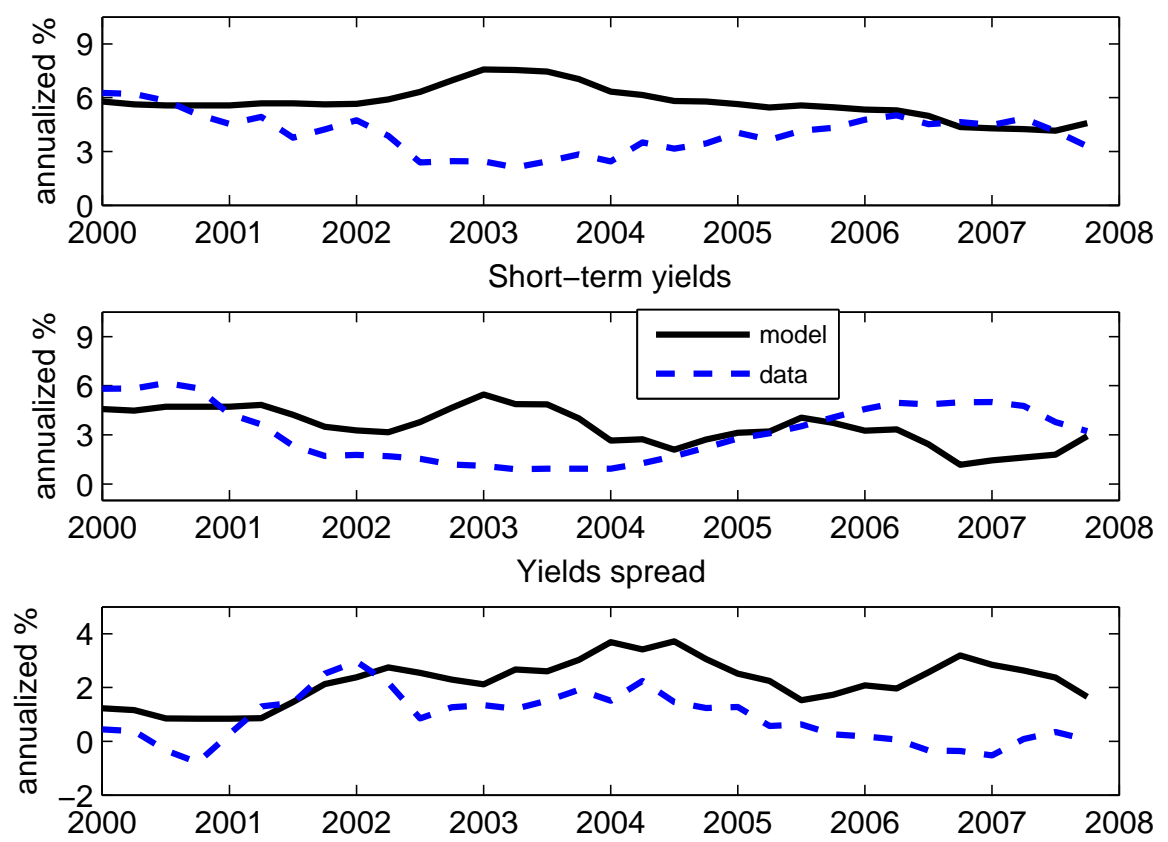

long-term simulated yields above the ones in the data. During this period the Fed kept fed funds target rate low, which has been cited as one of the causes for the housing boom and posterior bust in the U.S ${ }^{47}$ My model abstracts from monetary policy, only capturing those developments as long as they are reflected in movements of expected inflation. The yields spread in the model mimics its hump-shape version in the data until 2005Q2, capturing the initial increase and posterior decrease observed in the data. After that date the yield spread in the data continues declining until 2007, and the slope in the model first increases and then falls.

While the long-term yield in the data falls by 2.98pp during this period, the simulated long-term yield captures part of this decline, falling by 1.41pp. In contrast to the data, however, the yield slope grows by $0.44 \mathrm{pp}$ in the model, calculated as the change from the beginning to the end of this period, while there is a decrease of $0.39 \mathrm{pp}$ in the data. Below, I analyze the yield slope behavior in more detail, decomposing it into an expected component and a risk premium.

The paths for yields presented so far are the equilibrium response to all the exogenous variables varying simultaneously. To isolate the effect from foreign purchases on yields, I assume that foreign

${ }^{47}$ See, for example, Taylor (2007). 
holdings over GDP stay constant at the 2000Q1 level and compare path for yields in this case with the one in which foreign holdings behave as in the data.

Constant foreign holdings. Above I compared the implied path for yields when the agent in the model is subject to the shocks observed in the U.S. from 2000Q1 to 2007Q4. While this is instructive to learn the overall fit of the model, it is not possible to isolate the effect of foreign purchases using this exercise. To do this, I design a counterfactual experiment, asking what would have been the effects in yields if foreign holdings had stayed constant in terms of GDP 48 Figure 5 shows the results for this experiment. The figure reproduces the lines for the data and the model, and adds red lines for the yields implied by this counterfactual.

Figure 5: Nominal yields and yield curve slope, if $\Delta f_{t}=0$

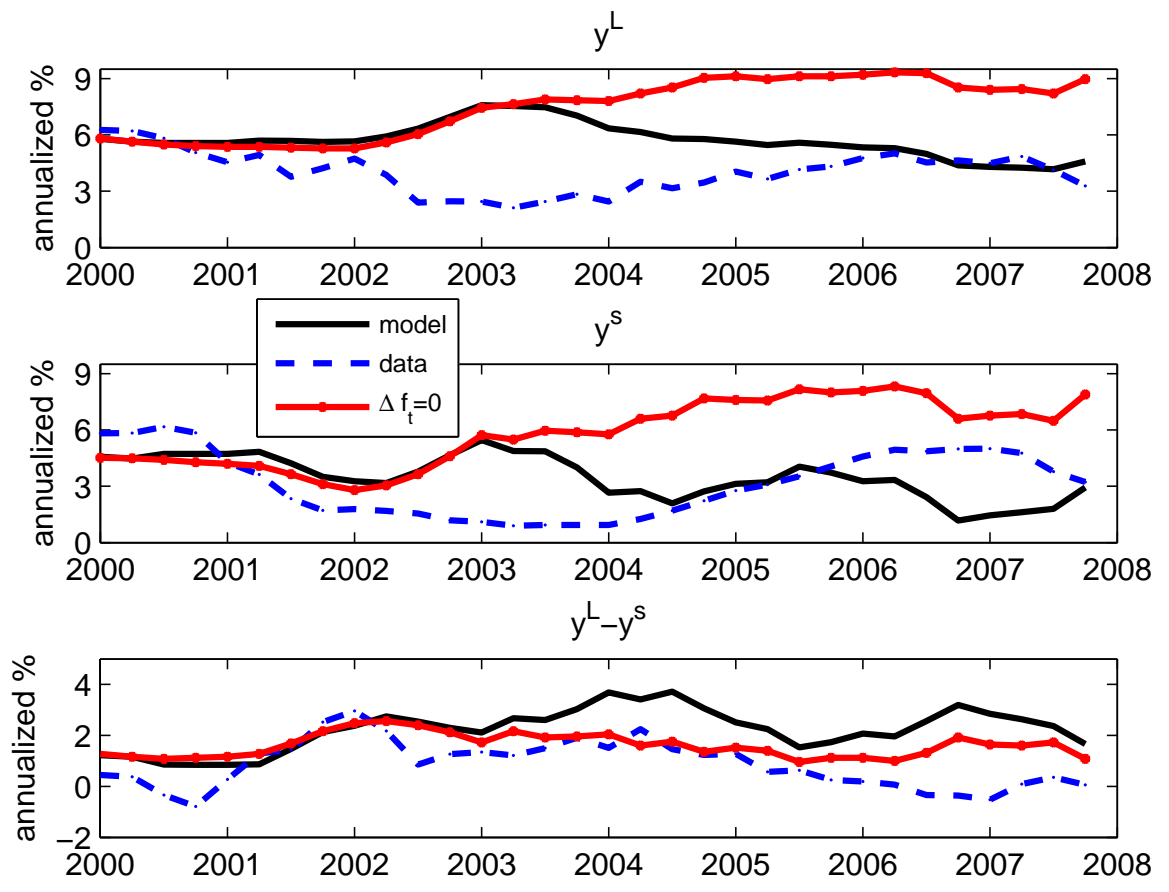

In the hypothetical path with constant foreign holdings, both long-term and short-term yields follow closely the corresponding yields with positive foreign purchases until 2003Q1, but then their paths separate from each other: the yields for the counterfactual get further away from the data counterparts. The long-term bond yield, in the case of constant foreign holdings, increases by 3.16 percentage points over the full period, while the short-term yield increases by 3.36pp. As a result,

\footnotetext{
${ }^{48}$ That is, I analyze the response of yields to a particular string of shocks such that $\Delta f_{t}=0$ over this period.
} 
however, the yield slope decreases by $0.20 \mathrm{pp}$, and its path is closer to the one in the data.

Table 4 provides information of the changes in yields, calculated as the difference from the beginning to the end of this period. The top panel is for nominal yields and the bottom one is for real yields. The first three rows of the panel above present the total changes for the lines shown in Figure 5. The fourth row presents the total change due to foreign holdings: it compares the change in yields implied by the model, with the change in yields if foreign holdings had stayed constant instead. According to the information in this row, foreign holdings decreased long-term nominal yields by 4.37 percentage points, and short-term yields by $5.01 \mathrm{pp}$, therefore increasing the yield spread in 0.64pp. Comparing both panels, nominal and real yields experiment similar variations: the mechanism through which foreign purchases affect yields in the model is a real phenomenon.

Table 4: Changes 2000Q1 to 2007Q4 in yields and spread

\begin{tabular}{lccc} 
& \multicolumn{3}{c}{ Nominal yields } \\
& $y^{S}$ & $y^{L}$ & $y^{L}-y^{S}$ \\
Data & -2.59 & -2.98 & -0.39 \\
Model & -1.65 & -1.21 & +0.44 \\
$f_{t}=f_{2000 Q 1}$ & +3.36 & +3.16 & -0.20 \\
\hline Due to $f_{t}$ & $\mathbf{- 5 . 0 1}$ & $\mathbf{- 4 . 3 7}$ & $+\mathbf{0 . 6 4}$ \\
& \multicolumn{3}{c}{ Real yields } \\
& \multicolumn{3}{c}{} \\
Data & -2.57 & -2.70 & -0.13 \\
Model & -2.26 & -1.93 & +0.33 \\
$f_{t}=f_{2000 Q 1}$ & +2.86 & +2.98 & +0.12 \\
\hline Due to $f_{t}$ & $\mathbf{- 5 . 1 2}$ & $\mathbf{- 4 . 9 1}$ & $\mathbf{+ 0 . 2 1}$
\end{tabular}

So far, I have shown the implications of the model for yields. The results suggest that foreign holdings actually increase the yield slope. This is due to the disproportionate response of shortterm yields. In the following, I decompose the yield slope to analyze the effect of foreign purchases on the term-premium.

Bonds term-premium. In this section, I decompose the yield spread in the model, and study the contribution of the term-premium to movements in long-term yields and the yield spread.

The term-premium on long-term bonds is the risk compensation required by risk-averse agents 
to hold a risky bond. Long-term bonds are risky if their prices covary negatively with consumption growth, so an agent that might need to sell the bond before maturity would suffer capital losses precisely in those moments where he wants to consume the most -in recessions. In the model, this negative covariance is caused by short-term interest rates increasing when surplus consumption is low, so that bond prices are lower in bad times. This makes both real and nominal bonds risky. Furthermore, there is an additional risk premium that affects nominal bonds, due to the negative correlation between inflation shocks and endowment growth shocks, as estimated from the data.

Not only long-term bonds are risky in the model, but the term-premium moves countercyclically, as in the data 49 In the model, this is due to the time-varying risk-aversion, which induces agents to require a higher term-premium in recessions than in expansions.

Define the term-premium as the yield of the long-term bond minus the yield on the expected discounted value of the coupons, discounted using the risk-free rate rather than the stochastic discount factor. This is the cleanest concept of risk-premium (Rudebusch and Swanson 2008), although it cannot be directly observed in the data. Then,

$$
\begin{aligned}
T P_{t} & =y_{t}^{L}-\widetilde{y}_{t}^{L} \\
& =\log \left(\frac{1+\delta q_{t}^{L}}{q_{t}^{L}}\right)-\log \left(\frac{1+\delta \widetilde{q}_{t}^{L}}{\widetilde{q}_{t}^{L}}\right)
\end{aligned}
$$

where $\widetilde{q}_{t}^{L}$ is the risk-neutral bond price. The risk-neutral bond price is the price of the long-term bond for a risk-neutral agent. As I show in the mechanism section below, it is a weighted average of the current and expected future short-term yields.

Given this definition, the yield curve slope can be decomposed as:

$$
\underbrace{y_{t}^{L}-y_{t}^{S}}_{\text {Yield slope }}=\underbrace{\widetilde{y}_{t}^{L}-y_{t}^{S}}_{\text {risk-neutral }}+\underbrace{y_{t}^{L}-\widetilde{y}_{t}^{L}}_{\text {TP }}
$$

Figure 6 presents the results of this decomposition for nominal yields. The top figure is the decomposition implied by the model for the yield spread when the exogenous variables move as in the data, while the bottom figure presents the results for the counterfactual with constant foreign holdings. The black solid line with squares is the yield spread, which can be decomposed into two $\overline{{ }^{49} \text { For example, Cochrane and Piazzesi (2005) }}$ and Ludvigson and Ng (2009). 
components: the difference between the risk-neutral yield and the short-term yield, given by the black dashed line, and the term-premium, represented by the black solid line. The blue dashed line is the yield spread in the data.

Figure 6: Nominal yield spread decomposition

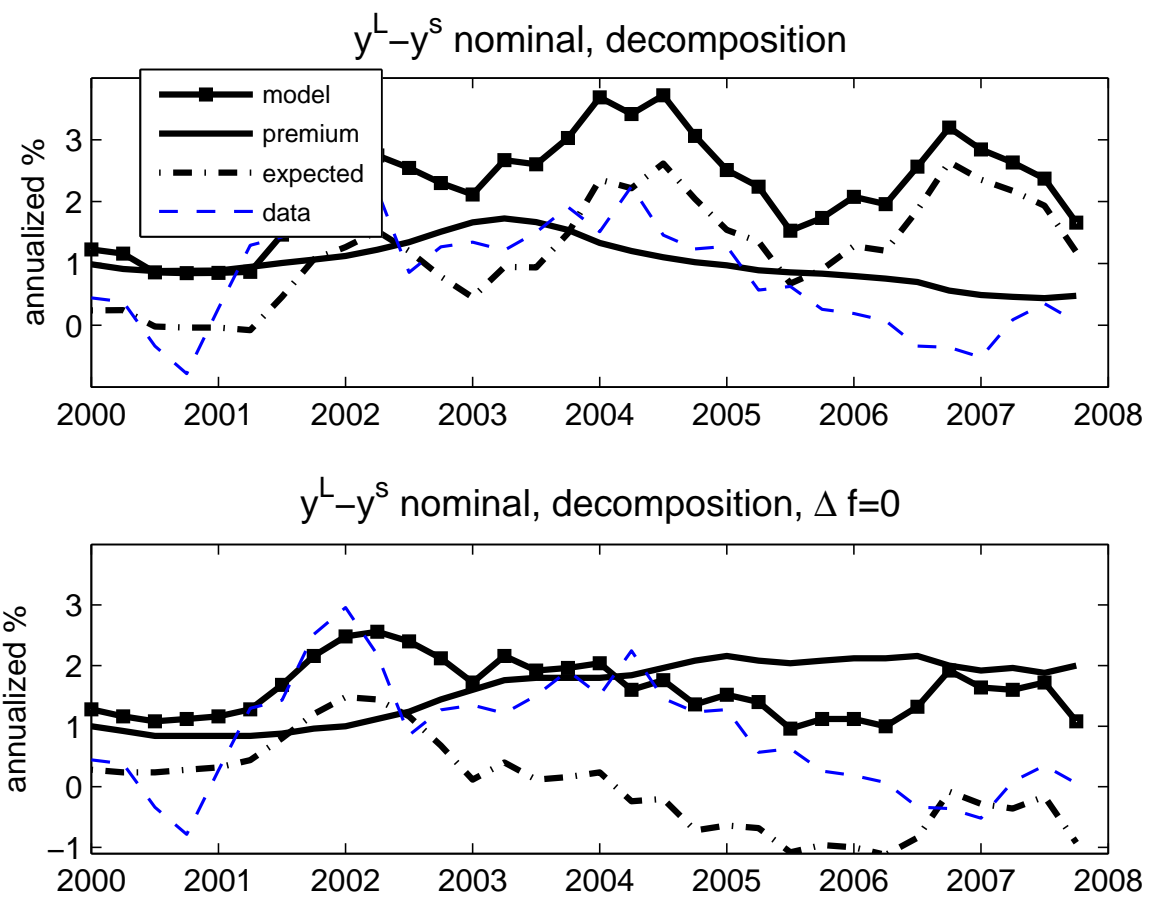

The term-premium captures the low-frequency movements in the yield spread. As shown in the top figure, it first increases until 2003Q2, and then decreases. From the beginning to the end of this period, it falls by $0.51 \mathrm{pp}$. The current and expected future short-term yields instead capture the higher frequency variation, and their movements are driven by changes in the short-term yield, which responds to shocks to expected inflation and expected consumption growth.

The bottom panel in Figure 6 shows the same decomposition when foreign holdings are constant in terms of GDP. In this case, the term-premium increases until the end of the sample, being 1.02pp higher at the end of the period. The yield slope decreases, however, driven by an increase in the short-term interest rate.

Table 5 summarizes these results. It shows the changes from the beginning to the end of this period for each of these lines, for both nominal and real yields. As noted above, the term-premium decreases over this period by $0.51 \mathrm{pp}$. Therefore, the increase in the yield slope is explained by a 
Table 5: Bond Yield Risk Premium

Nominal yields

\begin{tabular}{lccc} 
& $y^{L}-y^{S}$ & $\widetilde{y}^{L}-y^{S}$ & $T P$ \\
Model & +0.44 & +0.95 & $\mathbf{- 0 . 5 1}$ \\
$f_{t}=f_{2000 Q 1}$ & -0.20 & -1.22 & $\mathbf{+ 1 . 0 2}$ \\
\hline Due to $f_{t}$ & $\mathbf{+ 0 . 6 4}$ & $\mathbf{+ 2 . 1 7}$ & $\mathbf{- 1 . 5 3}$ \\
\multicolumn{3}{c}{ Real yields } \\
Model & +0.33 & +0.85 & $\mathbf{- 0 . 5 2}$ \\
$f_{t}=f_{2000 Q 1}$ & +0.12 & -1.01 & $\mathbf{+ 1 . 1 3}$ \\
\hline Due to $f_{t}$ & $\mathbf{+ 0 . 2 1}$ & $\mathbf{+ 1 . 8 6}$ & $\mathbf{- 1 . 6 5}$
\end{tabular}

more than proportional increase in the difference between the risk-neutral long-term bond yield, and the short-term yield. This difference increases because the short-term yield falls by more than the weighted average of future expected short-term yields. Real yields tell a similar story. If these results are compared to the case with constant foreign holdings, they suggest that foreign holdings decreased the term-premium by 1.53 percentage points over this period. In the next subsection, I analyze the mechanism through which foreign purchases of U.S. treasuries affect bond yields and the term-premium.

\subsection{Mechanism}

The model implies that there was a decrease in yields and in the term-premium from 2000Q1 to 2007Q4, but, had foreign holdings stayed constant in terms of GDP over this period, there would have been an increase in yields and risk premium instead. In this subsection, I discuss the main channels through which foreign purchases of U.S. Treasuries affect bond yields.

Foreign purchases and short-term yields. On the one hand, high foreign purchases diminish expected consumption growth, reducing real one-period yields. Equation 12 shows how these two 
variables are related in the model 50

$$
\begin{aligned}
E_{t}\left(\Delta c_{t+1}\right) \approx & E_{t}\left(q_{t+1}^{a} f_{t+1}-q_{t}^{a} f_{t}\right)+E_{t}\left(\Delta y_{t+1}\right) \\
& \quad-E_{t}\left[\left(1+(1-\alpha) \delta q_{t+1}^{L}\right) f_{t} e^{-\left(\Delta y_{t+1}+\pi_{t+1}\right)}-\left(1+(1-\alpha) \delta q_{t}^{L}\right) f_{t-1} e^{-\left(\Delta y_{t}+\pi_{t}\right)}\right]
\end{aligned}
$$

First, notice that without foreign holdings $\left(f_{t}=0 \forall t\right)$, expected consumption growth depends only on expected endowment growth. Since endowment growth has very low persistence according to my calibration, expected consumption growth barely moves in this case. Given non-zero foreign holdings, there are two extra terms: the expected change in the value of foreign purchases from $t$ to $t+1, E_{t}\left(\Delta\left(q_{t+1}^{a} f_{t+1}\right)\right){ }^{51}$ and the burden of past debt that needs to be paid at $t$ minus what was paid at $t-1$. As I show below, the latter is the dominant term in the period 2000Q1-2007Q4, given the stochastic process for foreign holdings and endowment growth. Therefore, expected consumption growth covaries negatively with foreign purchases at $t, \Delta f_{t}$.

The burden of past debt also varies with changes in inflation or endowment growth (since foreign debt is normalized by the endowment), and contains the price of long-term debt, since the stock of long-term debt appreciates or depreciates with its price. That is, this model can potentially account for some of the big valuations effects observed in the data over the last decade.

The expected change in the value of foreign purchases from $t$ to $t+1$ is not quantitatively important. First, the process estimated for $f_{t}$ is close to a unit root process, $E_{t}\left(\Delta f_{t+1}\right) \approx 0[52$ On the other hand, variation in the bond prices, $E_{t}\left(\Delta q_{t+1}^{a}\right)$, is quantitatively small, as I show below 53

The discussion above suggests that foreign purchases reduce expected consumption growth. To understand the effects of changes in expected consumption growth on short-term yields, I derive below an expression for the short-term real yield. Deriving the expression for the (log) stochastic discount factor of the model, and assuming for exposition motives that consumption growth is approximately log-normally distributed, the real short-term yield can be expressed as 54

$$
\begin{aligned}
& y_{t}^{s}=-\log \left(E_{t}\left(e^{m_{t+1}}\right)\right) \\
& y_{t}^{s} \approx-\log (\beta)+\gamma E_{t}\left(\Delta c_{t+1}\right)+b\left(\bar{s}-s_{t}\right)-\frac{\gamma(1-\phi)-b}{2}
\end{aligned}
$$

50 The approximation I am using here is $\log (1+x) \approx x$.

${ }^{51} q_{t}^{a}$ is the average price of a bond at $t$, i.e. $q_{t}^{a}=\alpha q_{t}^{s}+(1-\alpha) q_{t}^{L}$.

52 Actually, it is negative due to slow mean reversion of foreign holdings.

${ }^{53}$ Notice that $E_{t}\left(q_{t+1}^{a} f_{t+1}-q_{t}^{a} f_{t}\right)=q_{t}^{a} E_{t}\left(\Delta f_{t+1}\right)+f_{t} E_{t}\left(\Delta q_{t+1}^{a}\right)+E_{t}\left(\Delta f_{t+1} \Delta q_{t+1}^{a}\right)$

${ }^{54}$ This is the case in Wachter (2006) specification, where consumption is a random walk, but not here, due to the presence of non-zero foreign debt and a small predictable component in consumption growth. 
A drop in expected consumption growth decreases short-term interest rates, with the magnitude of this effect given by the inverse of the intertemporal elasticity of substitution.

Figure 7: Short-term real yield and $E_{t}\left(\Delta c_{t+1}\right)$

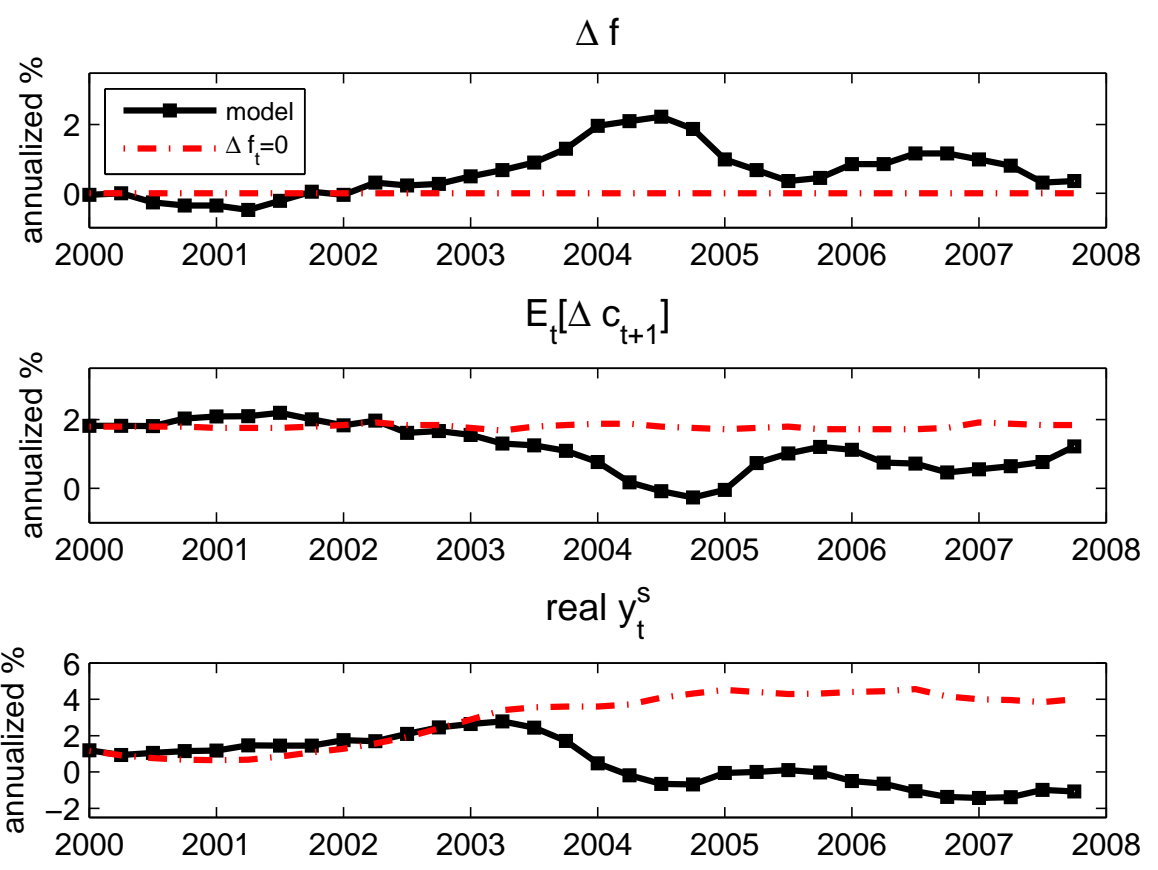

The black solid squared lines in the top two panels of Figure 7 show how expected consumption growth covaries negatively with foreign purchases in the simulation. The red dotted line represents the case when foreign holdings stay constant at their value at the beginning of the sample. In this case expected consumption growth barely moves. The bottom panel shows that the real short-term yield moves in the same direction as expected consumption growth, according to the model, and decreases after 2003Q2. Instead, they increase over the whole sample when foreign holdings stay constant, driven by surplus consumption as explained below.

The real short-term yield also depends on surplus consumption (Equation 13, with the sign and magnitude of their comovement depending on the parameter $b$. While this relationship is only linear on foreign purchases in this approximation, the sign and magnitude of the relationship between the real risk-free rate and surplus consumption still depends on $b 55$ If $b>0$, an increase

\footnotetext{
55 The function that measures the sensitivity of the surplus consumption to consumption growth innovations, $\lambda\left(s_{t}\right)$, is designed specifically so that the risk-free rate is linear in surplus consumption in the case that consumption is a random walk and is log-normally distributed.
} 
in $s_{t}$ drives short-term interest rates down, so the short-term yield is countercyclical and long-term bonds are risky, commanding a compensation for risk.

Foreign purchases, long-term yields and the term-premium. Foreign holdings affect longterm yields and the term-premium mainly through their effect on surplus consumption. Since surplus consumption is positively correlated with consumption growth innovations, it is important to understand how foreign purchases affect consumption growth innovations to study the effect of foreign purchases on long-term yields.

Figure 8 shows that the real long-term yield and the term-premium covary negatively with surplus consumption. Here also, the black solid squared lines represent the paths implied by the model, when the agent is subject to the same shocks observed in the U.S. during this period, and the red lines represent the counterfactual paths if foreign holdings stay constant at their 2000Q1 level.

Figure 8: Long-term real yield and $s_{t}$
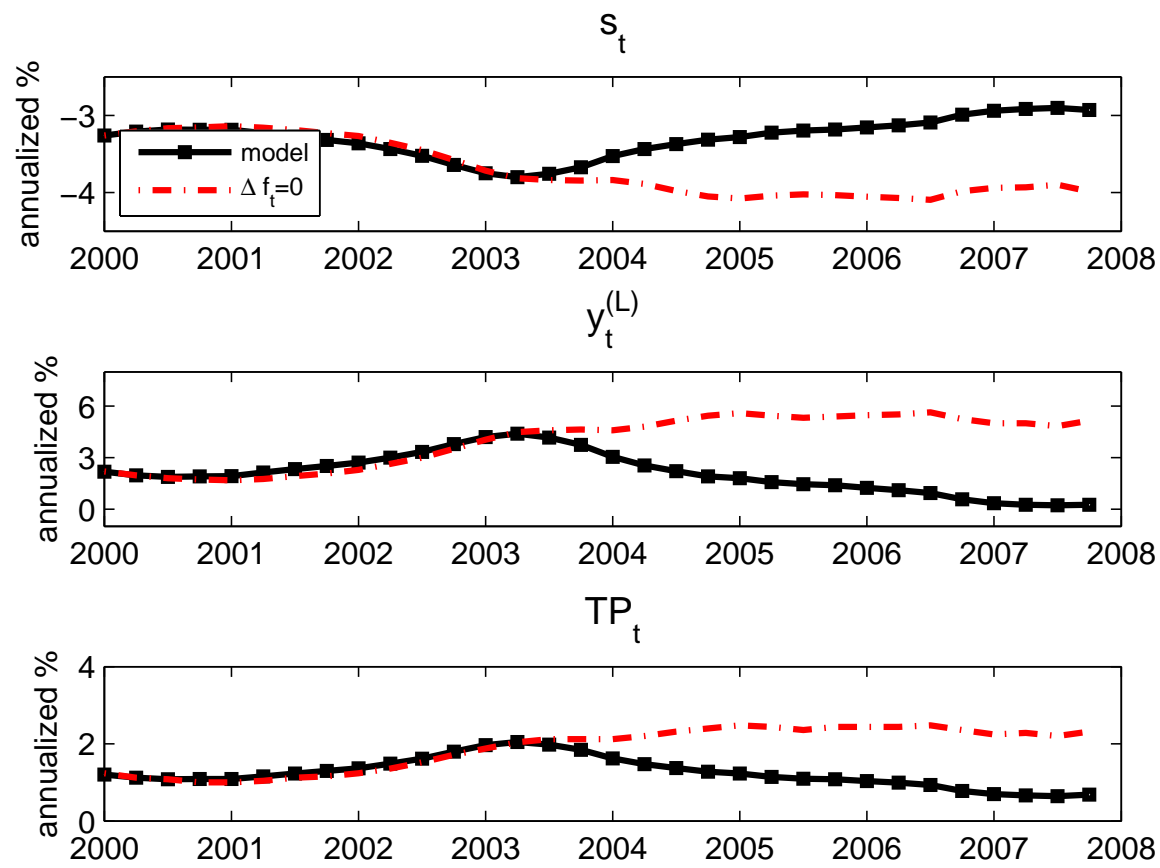

To understand the relationship between surplus consumption and long-term yields, I decompose the long-term bond price as the sum of a risk-neutral price and a second component inversely related 
to the term-premium 56 and show how surplus consumption affects each of these components. For the explanation I focus on prices instead of yields since it is easier to get intuition from the prices. Equation 14 shows this decomposition.

$$
q_{t}^{L}=\widetilde{q}_{t}^{L}+\left(q_{t}^{L}-\widetilde{q}_{t}^{L}\right)
$$

The risk-neutral part is a weighted average of one-period bond prices both at $t$ and expected in the future.

$$
\begin{aligned}
& \widetilde{q}_{t}^{L}=\sum_{i=0}^{\infty} \delta^{i} Q_{t+1+i}^{s} \\
& \widetilde{q}_{t}^{L}=q_{t}^{s} E_{t}\left(1+\delta \widetilde{q}_{t+1}^{L}\right)
\end{aligned}
$$

where $Q_{t+i}^{s}$ is the risk-neutral price at t of a unit of consumption at $t+i$. i.e., $Q_{t}^{s}=1, Q_{t+1}^{s}=q_{t}^{s}$, $Q_{t+2}^{s}=q_{t}^{s} E_{t}\left(q_{t+1}^{s}\right)$, and so on.

The same variables that determine the short-term bond yield affect each of these prices. However, since surplus consumption is very persistent, $\phi=0.97$, it ends up dominating the other effects. An increase in surplus consumption decreases current and future short-term yields and increases one-period bond prices, causing a drop in risk-neutral yields.

On the other hand, the risk premium component can be written as a sum of covariances between future bond prices and future values of the nominal stochastic discount factor. The covariances between prices and pricing kernels in the future are discounted by $\delta^{t+1}$.

$$
\begin{aligned}
& q_{t}^{L}-\widetilde{q}_{t}^{L}=q_{t}^{s} \delta E_{t}\left[q_{t+1}^{L}-\widetilde{q}_{t+1}^{L}\right]+\delta \operatorname{Cov}_{t}\left(M_{t+1}^{\$}, q_{t+1}^{L}\right) \\
& q_{t}^{L}-\widetilde{q}_{t}^{L}=\sum_{i=0}^{\infty} \delta^{1+i} \operatorname{Cov}_{t}\left(M_{t+1+i}^{\$}, q_{t+1+i}^{L}\right) Q_{t+i}^{s}
\end{aligned}
$$

Notice that if the covariances between the stochastic discount factor (SDF) and the bond price are negative, both in the present and in the future, the price of a long-term bond is lower than the risk-neutral price of the same bond. This implies that its yield is higher than its risk-neutral counterpart, generating a positive term-premium. For the covariance between the pricing kernel and the bond price to be negative, the covariance between consumption growth and the bond price

\footnotetext{
${ }^{56}$ If the price of a long-term bond is lower than its risk-neutral counterpart, this term is negative, and the termpremium is positive.
} 
needs to be positive. That is, the term-premium is positive if the bond price is low in states of low consumption growth (i.e., in recessions), and high when consumption growth is high.

Each of these covariances can be written as:

$$
\operatorname{Cov}_{t}\left(M_{t+1+i}^{\$}, q_{t+1+i}^{L}\right)=\rho_{t}\left(M_{t+1+i}^{\$}, q_{t+1+i}^{L}\right) \sigma_{t}\left(M_{t+1+i}^{\$}\right) \sigma_{t}\left(q_{t+1+i}^{L}\right)
$$

In this model, the driving force behind the variation over time of these covariances is the countercyclical risk aversion. An increase in surplus consumption reduces the risk aversion of the agents, given by $\frac{\gamma}{S_{t}}$, and the market price of risk:

$$
\frac{\sigma_{t}\left(M_{t+1}\right)}{E_{t}\left(M_{t+1}\right)} \approx \sigma_{t}\left(m_{t+1}\right)=\gamma\left(1+\lambda\left(s_{t}\right)\right) \sigma_{\Delta c, t}
$$

Notice that $\lambda\left(s_{t}\right)$ is negatively correlated with surplus consumption.

The discussion above suggests that the risk-neutral prices and the term-premium are driven by surplus consumption. To understand what causes the changes in bond prices, we need to understand what drives surplus consumption. Surplus consumption is positively correlated with consumption growth innovations: when these innovations are positive, surplus consumption increases, and when they are negative, it decreases. Figure 9 depicts this relationship for the period 2000Q1-2007Q4.

Figure 8 and Figure 9 show how long-term yields and the term-premium are driven by surplus consumption, and movements in surplus consumption are caused by innovations in consumption growth. Therefore, to understand the effects of foreign purchases on long-term yields, I study below how foreign purchases affect consumption growth innovations.

$$
\begin{aligned}
\epsilon_{t+1}^{\Delta c} \approx & \Delta y_{t+1}-E_{t}\left(\Delta y_{t+1}\right) \\
& -f_{t}\left[\left(1+(1-\alpha) \delta q_{t+1}^{L}\right) e^{-\left(\Delta y_{t+1}+\pi_{t+1}\right)}-E_{t}\left(\left(1+(1-\alpha) \delta q_{t+1}^{L}\right) e^{-\left(\Delta y_{t+1}+\pi_{t+1}\right)}\right)\right] \\
& +\left(q_{t+1}^{a} f_{t+1}-q_{t}^{a} f_{t}\right)-E_{t}\left(q_{t+1}^{a} f_{t+1}-q_{t}^{a} f_{t}\right)
\end{aligned}
$$

Equation 16 decomposes consumption growth innovations in three terms: the unexpected change in endowment growth, the unexpected change in the value of foreign holdings at $t$, and the unexpected change in the value of foreign holdings from $t$ to $t+1$. The first term, innovations in endowment growth, is given approximately by the endowment growth, since the endowment is 
Figure 9: Surplus consumption and consumption growth innovations
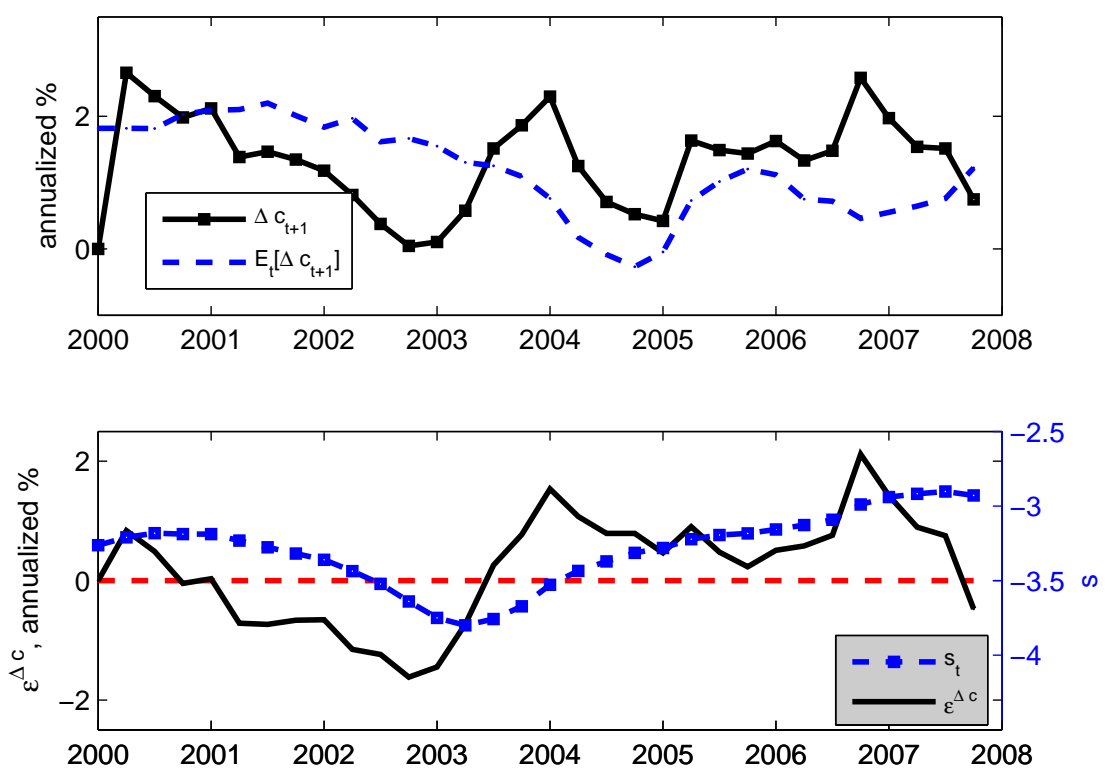

almost a random walk in my calibration.

The second term measures the unexpected changes in the value of debt. An unexpected increase in the price of long-term bonds increases the amount that needs to be paid back at $t+1$, given the same quantity of bonds. An unexpected increase in inflation, instead, diminishes the burden of the debt at $t+1$ for the domestic agent. Finally, positive endowment growth reduces foreign holdings in terms of the endowment.

The last term is the unexpected change in the value of foreign holdings (price times quantity) from $t$ to $t+1$. This term is approximately $\Delta f_{t+1}$, as I show below. Since $f_{t}$ is close to a unit root process, foreign purchases at $t+1$ are almost completely unexpected: $\Delta f_{t+1}-E_{t}\left(\Delta f_{t+1}\right) \approx$ $\Delta f_{t+1}$. Since new foreign purchases $\Delta f_{t+1}$ are unexpected, they produce positive innovations to consumption growth. These innovations accumulate, increasing the persistent surplus consumption, which reduces long-term yields and the term-premium.

As Figure 9 shows, surplus consumption decreases until 2003Q2, and then increases until the end of the sample. What caused the negative innovations in consumption growth in the first part of the sample, and the positive innovations after 2003Q2? To answer this question, Figure 10 shows the decomposition of consumption growth innovations for this period, given by the black solid line. 
Figure 10: $\Delta c$ unexpected changes decomposition

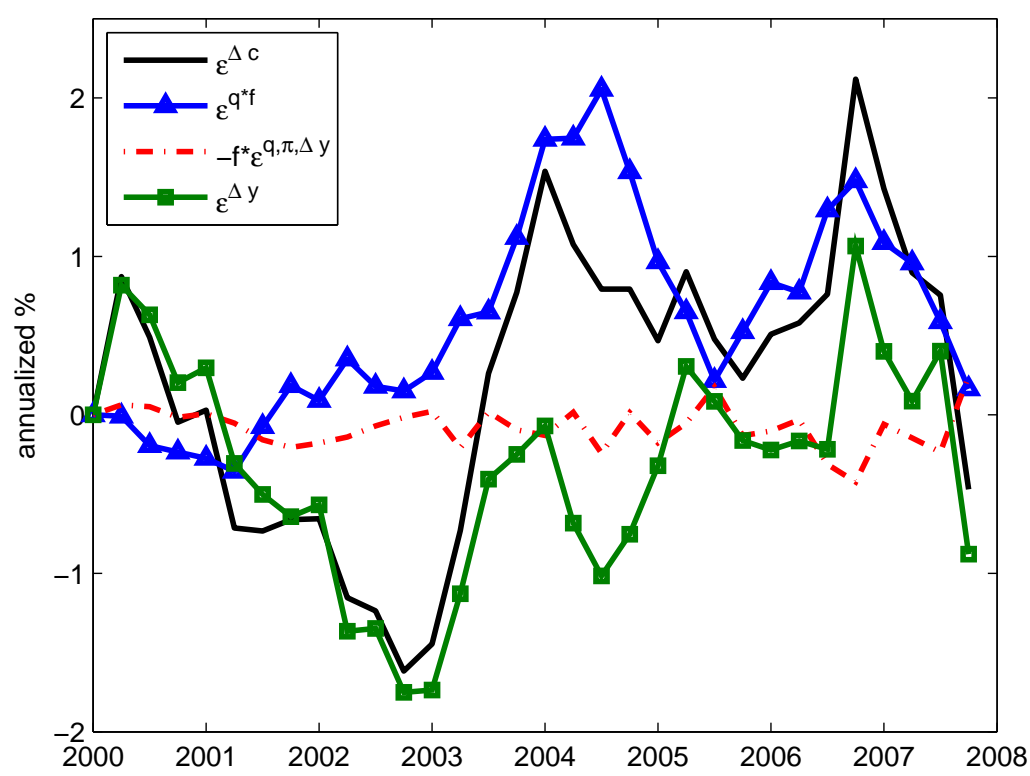

As can be seen in the figure, this line moves almost one-to-one with the dashed green line, which stands for the innovations to endowment growth, until 2003Q2. This suggests that the decrease in surplus consumption, on the first part of the sample, was caused by negative innovations to endowment growth.

After 2003Q2, the black line moves closer to the dotted blue line, which stands for the innovations to the value of foreign purchases. That is, the following decline in surplus consumption is driven by positive innovations to the value of foreign purchases. This is why, absent these foreign purchases, surplus consumption would continue to decrease, as shown above.

Finally, Figure 11 shows that innovations in the value of debt were indeed driven by changes in foreign purchases and not in prices. Each line in this figure corresponds to a different term in Equation 17 below:

$$
\begin{aligned}
\epsilon^{q f} & \equiv\left(q_{t+1}^{a} f_{t+1}-q_{t}^{a} f_{t}\right)-E_{t}\left(q_{t+1}^{a} f_{t+1}-q_{t}^{a} f_{t}\right) \\
& =\left(f_{t+1}-f_{t}\right) q_{t+1}^{a}+\left(q_{t+1}^{a}-q_{t}^{a}\right) E_{t}\left(f_{t+1}\right)-\operatorname{Cov}_{t}\left(q_{t+1}^{a}, f_{t+1}\right)
\end{aligned}
$$

In this subsection, I showed the main channels through which foreign purchases affect short-term yields and long-term yields. On the one hand, foreign purchases decrease expected consumption 
Figure 11: $\epsilon^{q x f}$ decomposition

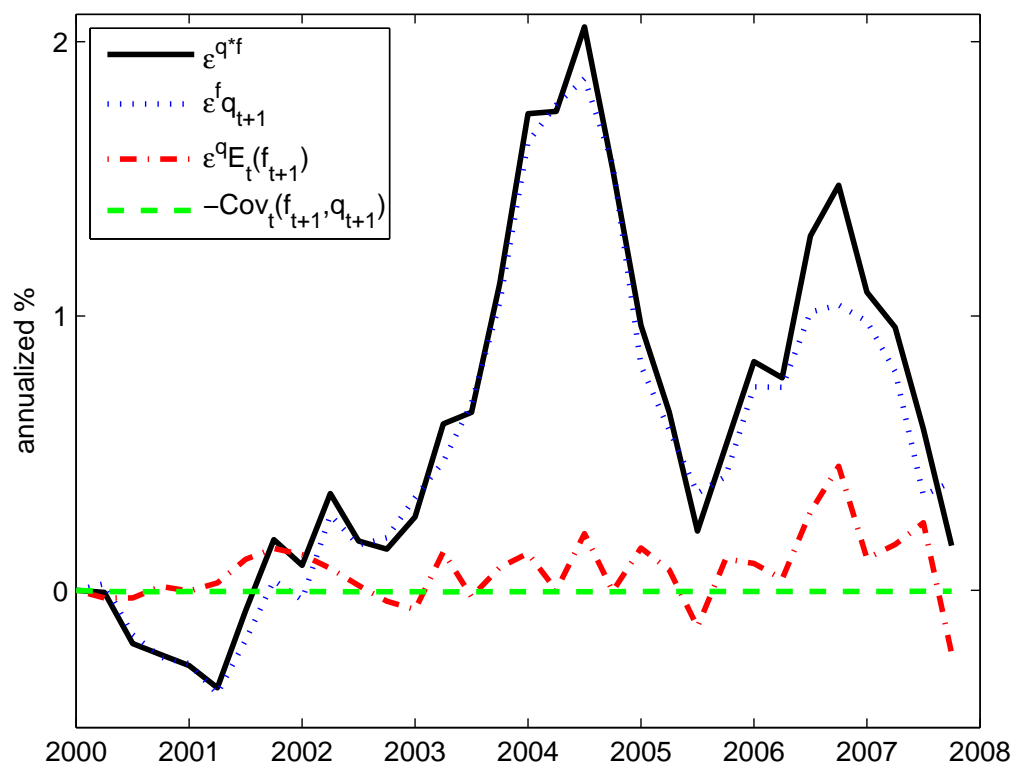

growth which reduces short-term yields. On the other, they produce positive innovations in consumption growth that increase surplus consumption. An increase in surplus consumption reduces both risk-neutral long-term yields, through its effect on future short-term interest rates, and the term-premium, through a drop in risk aversion. The model implies that from 2000Q1 to 2003Q2, long-term yields increased because of a fall in surplus consumption caused by negative endowment growth; after 2003Q2 until the end of the sample, long-term yields fell driven by positive innovations to consumption growth, caused by an increase in foreign purchases. In the next subsection, I use this model to analyze the possible consequences of a reversal of foreign holdings on long-term yields and the term-premium.

\subsection{A reversal of foreign purchases of U.S. Treasuries}

The dramatic increase in foreign demand for U.S. Treasuries has led to an unprecedented degree of foreign ownership. By June 2012, of the 8.9 trillion usd in marketable long-term U.S. Treasuries outstanding, 52.5 percent were foreign-owned. However, this percentage has been declining since the record high of 61.1 percent in June 2008. Of those foreign-owned, three-fourths were owned by foreign official institutions. Furthermore, China and Japan were jointly responsible for 46 percent 
of the total long-term U.S. Treasuries held by foreigners, being the largest of such owners. ${ }^{57}$

This high degree of foreign ownership has led many analysts to question the sustainability of this situation, and discuss the potential economic consequences of a sell-off of U.S. debt by foreign governments 58 In this section I use my model to provide an estimate for the effects of this sell-off on U.S. Treasury yields and risk premium.

For this counterfactual, I assume that Chinese and Japanese Official Institutions stop rolling over their holdings of U.S. Treasury debt, both short-term and long-term, beginning in June 2013. The speed of adjustment is given by the maturity structure of their holdings in the data 59 Since I lack data on the maturity structure of Chinese and Japanese FOI specifically, I use the maturity structure of overall FOI, as of June 2013. Because data on maturity is expressed yearly, I obtain movements between quarters as the linear interpolation of yearly values.

Furthermore, I assume that shocks to endowment growth and inflation are zero, and all the variation in these variables is coming from their interaction with foreign holdings, as obtained from the transition matrix $A$, above.

Finally, I normalize foreign holdings by nominal GDP, assuming that it increases at an annual rate of 4.8 percent, which is the sum of the 10-year ahead inflations expectations of $2.3 \%$ and real GDP growth for the next ten years of $2.5 \% \sqrt{60} \mathrm{I}$ assume that foreign holdings of all other countries stay constant in terms of GDP.

Figure 12 shows the path for the exogenous state variables in this exercise. $f_{t}$ falls from 23.8 percent of GDP to 13 percent of GDP in ten years. Since foreign holdings are mostly concentrated on short-maturities, almost half of this change happens in the first three years. Also notice that there is a large increase in inflation. This is because foreign holdings are higher than their historical mean (red dotted line in the ../Figures). Since foreign holdings have a positive impact on inflation, according to the estimated transition matrix, inflation increases over time before it starts a slow decrease at the end of the exercise, driven by mean reversion to its unconditional mean. Figure 13 presents the main results for nominal yields. The yields are expressed as differences with respect to

${ }^{57}$ I am including China mainland, Hong Kong and Japan. Data from http://www.treasury.gov/resource-center/ data-chart-center/tic/Documents/shla2012r.pdf

${ }^{58}$ Favilukis, Ludvigson, and Van Nieuwerburgh (2012a), Obstfeld and Rogoff (2010), Bernanke, Bertaut, DeMarco, and Kamin (2011), Farhi, Gourinchas, and Rey (2011)

${ }^{59} \mathrm{I}$ assume that the share of foreign official holdings is 75 percent in China and Japan, as the average share for the group of foreign holders.

${ }^{60}$ Median forecasts. Data from Survey of Professional Forecasters. 
Figure 12: Path for exogenous variables

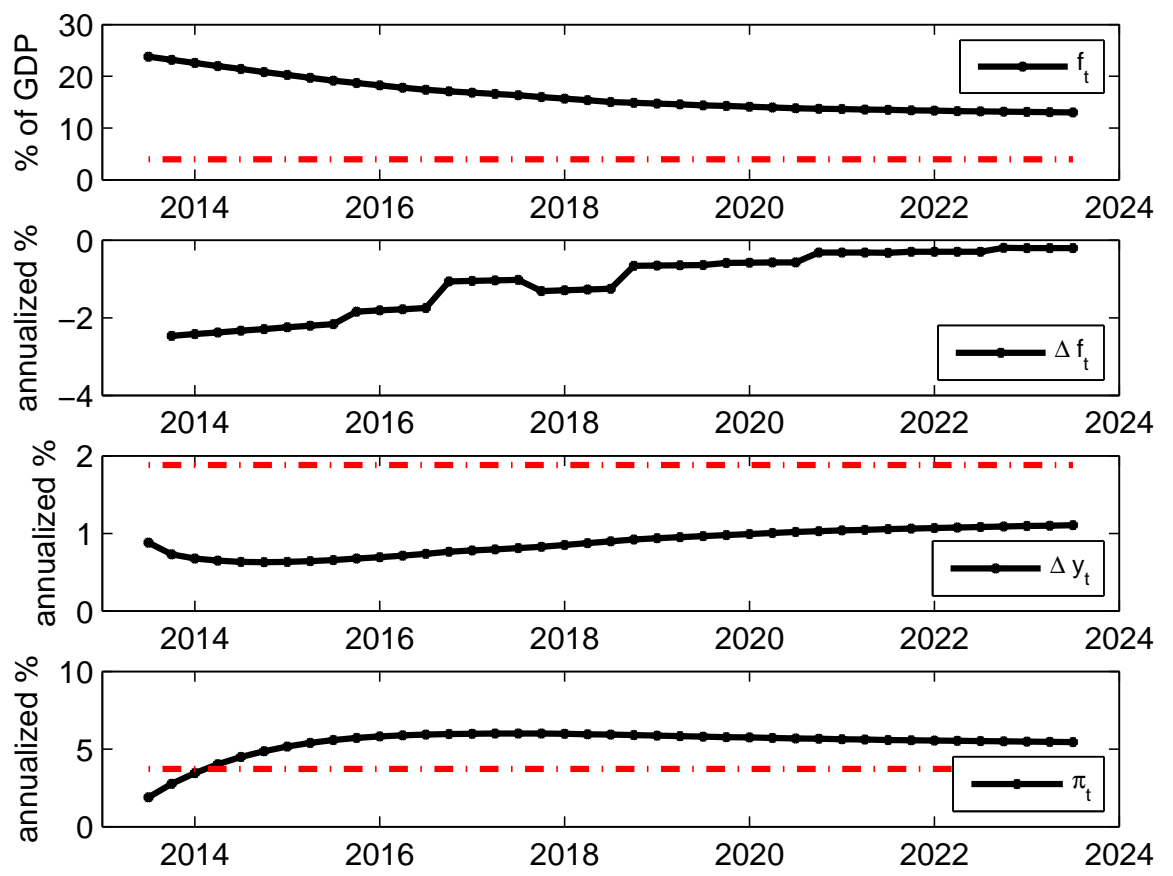

their value at 2013Q2. Long-term yields increase by 7.4 percentage points in ten years, but almost 5 percentage points of this increase occurs in the first three years. The term-premium increases by 2.6 percentage points in ten years, with 2.1 percentage points of this increase in the first three years, explaining more than 40 percent of the increase in long-term yields. The yield slope, however, first decreases sharply due to a large increase in short-term yields, but then increases slowly with the term-premium. The short-term nominal yield increases because of changes in expected inflation and expected consumption growth, that affect primarily the short end of the yield curve. This can be seen in Figure 15, that presents the movement in the state variables driving the prices in this economy.

Finally, as shown in Figure 14, real yields behave similarly to nominal yields, except that shortterm yields do not increase as much as their nominal counterpart, because they are not affected by expected inflation. Furthermore, notice that real long-term yields increase almost as much as nominal long-term yields, because expected inflation does not have a large impact on the long-end of the yield curve. The yield slope becomes positive, driven by the increase in the term-premium. 
Figure 13: Nominal long-term yields, yield slope and term-premium
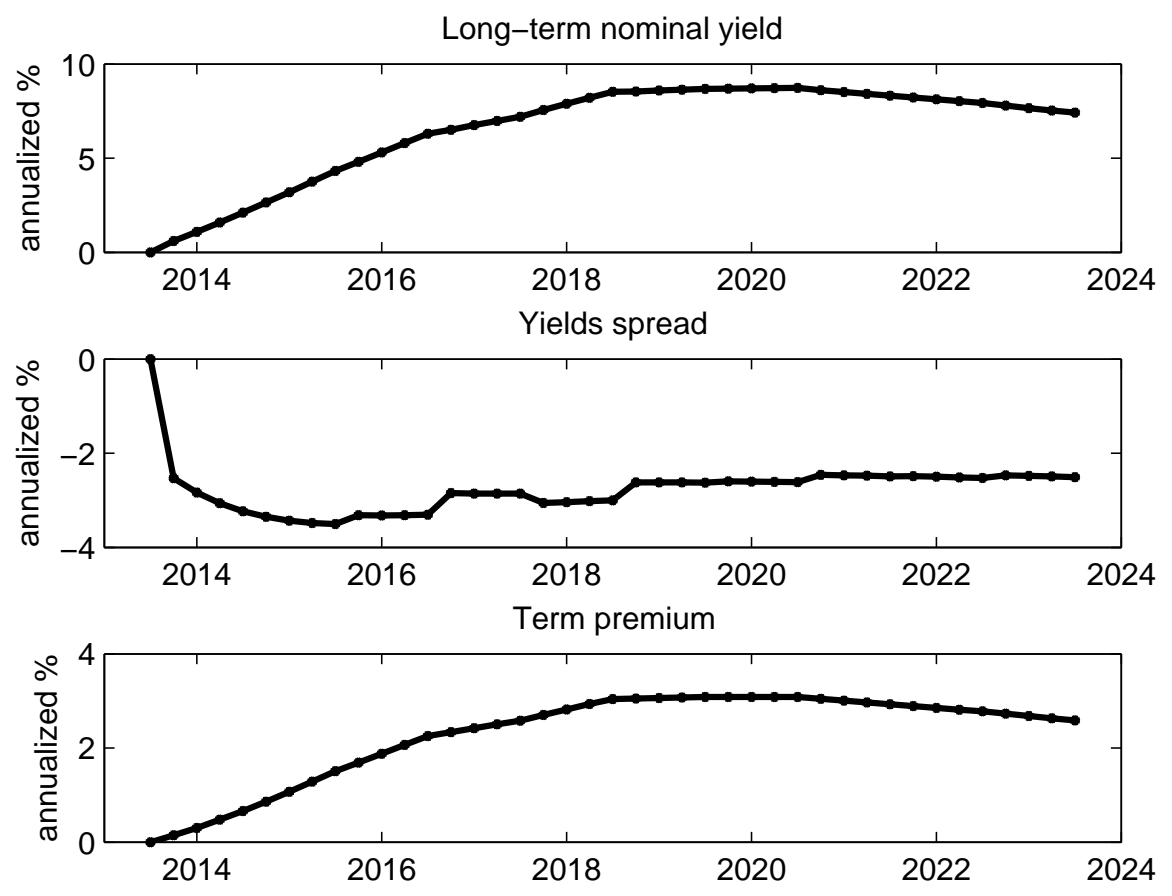

Figure 14: Real long-term yields, yield slope and term-premium
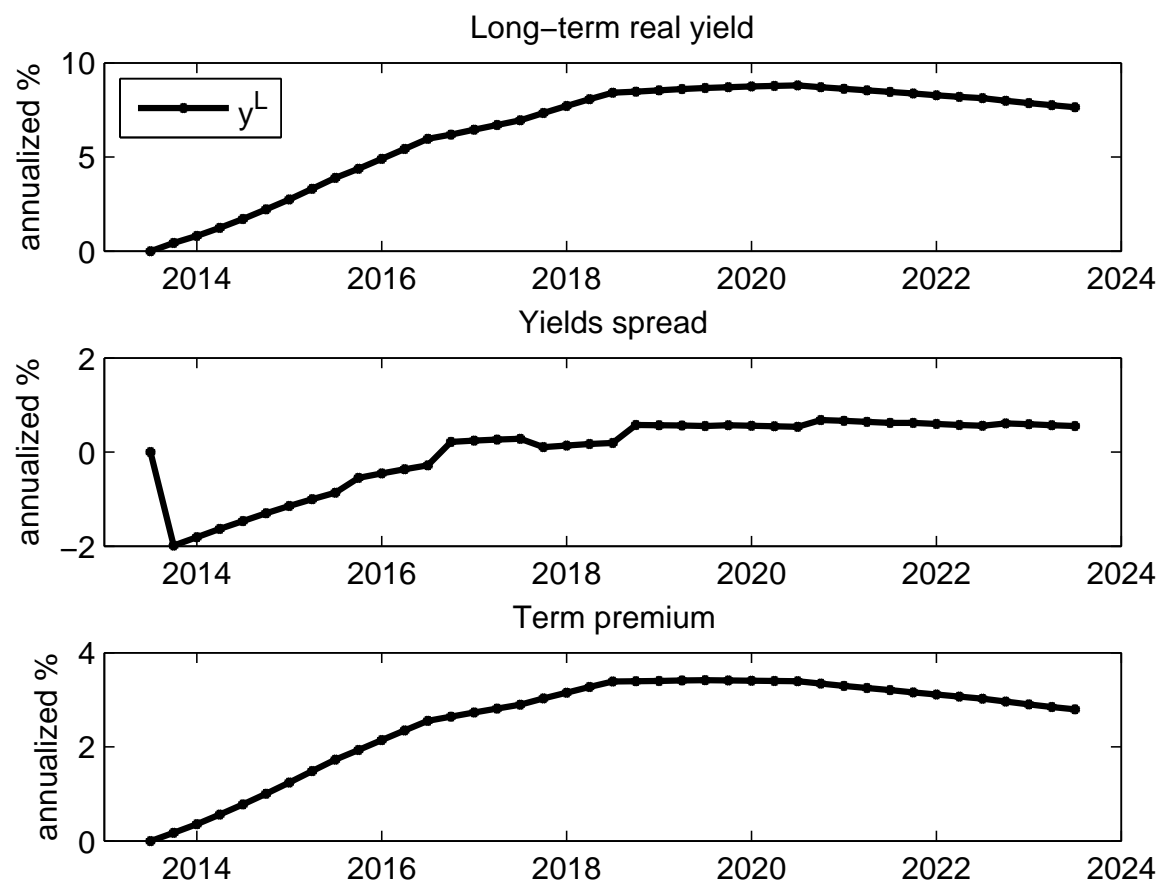
Figure 15: $E_{t}\left[\Delta c_{t+1}\right], s_{t}$ and $E_{t}\left[\pi_{t+1}\right]$
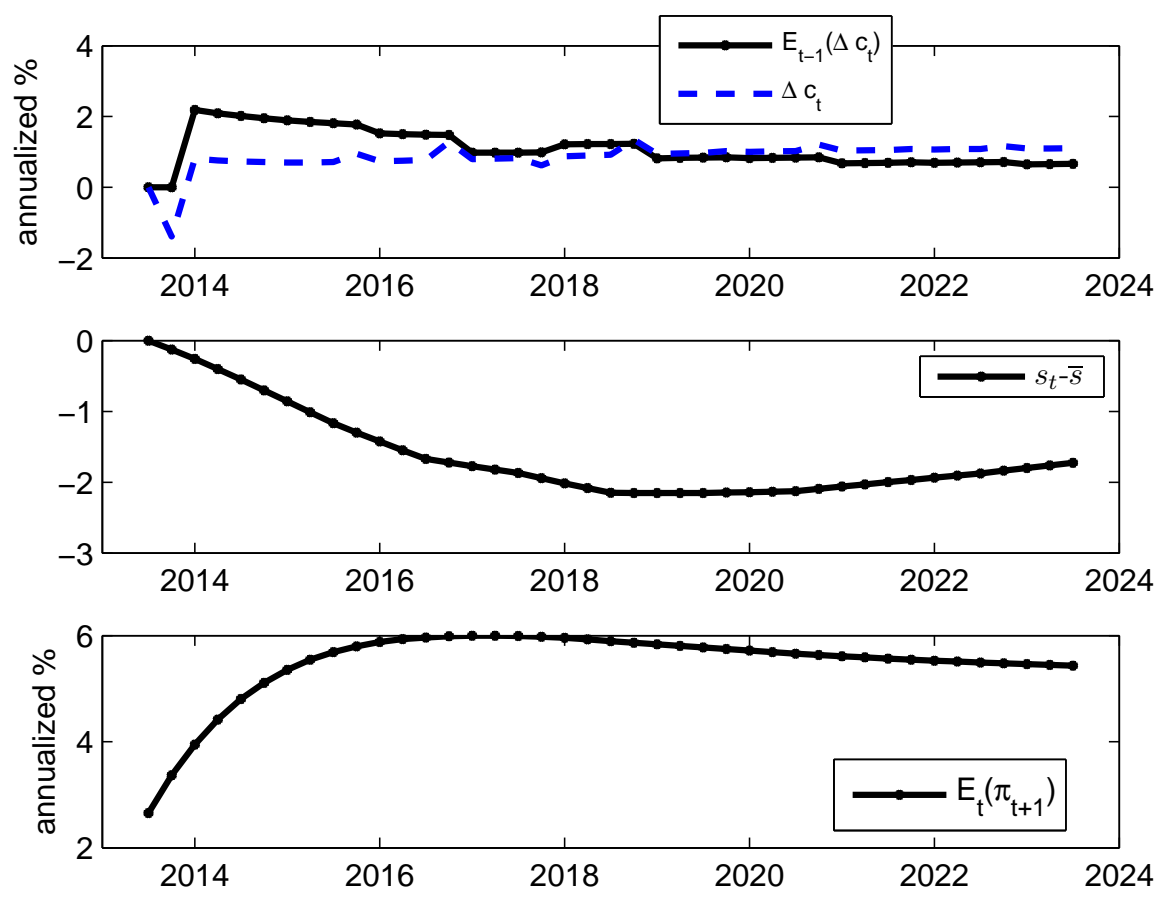

\section{Conclusion}

Foreign holdings of U.S. Treasuries increased dramatically over the last two decades, driven primarily by Foreign Official Institutions. Recent empirical papers suggest that this surge in foreign holdings has contributed to the observed decline in both long-term yields and the term-premium. However, they are silent regarding the mechanism driving these effects. In this paper, I set up a consumption-based model to quantify the contribution of the term-premium to this decline, and investigate the reasons why foreign purchases reduce term-premia and long-term yields.

To this end, I model the domestic agent's preferences with external habits, which assumes that the agent values consumption relative to a reference level or past consumption. This feature implies a time-varying market price of risk. Furthermore, I allow for positive foreign holdings of bonds, which I estimate from U.S. data. Then, I use the model to study two questions: first, what was the effect of foreign purchases of U.S. treasuries on the term-premium during 2000Q1-2007Q4, and how much of the observed decline in long-term yields they can explain. Second, how a reversal of foreign inflows to U.S. treasuries would affect the term-premium and long-term yields.

The first quantitative exercise suggests that the surge in foreign holdings, by itself, decreased 
long-term yields by 4.37 percentage points from 2000Q1 to 2007Q4, with a large part of this change -1.53 percentage points- explained by a drop in the term-premium. Given the shocks to endowment growth and inflation during this period, however, the long-term yields in the model only decline by 1.21 percentage points, capturing 40 percent of the fall in yields in the data. Foreign purchases reduce long-term yields in the model because they increase consumption growth beyond its expected value, which drives up the difference between consumption and the habit. On the one hand, an increase in surplus consumption reduces current and future interest rates, given that surplus consumption is very persistent. On the other hand, it also reduces the risk aversion generating a drop in the term-premium. My results suggest that foreign purchases caused a decline in the term-premium since 2003Q2 until the end of the period.

Finally, I analyzed the hypothetical case where China's and Japan's Foreign Official Institutions stop rolling over their holdings of U.S. treasuries, reducing total foreign holdings over GDP from 24 percent to 13 percent over a ten-year period. In this case, long-term yields increase by 7.4 percentage points, beginning in June 2013, of which approximately one-third are explained by an increase in the term-premium.

I do not study the effects of monetary policy in this paper. In macroeconomic models with a Taylor rule, the short-term interest rate reflects the policy responses to shocks in nominal or real variables, which constrains its response to exogenous shocks. Introducing monetary policy in the current setup would be useful to study the role of interaction between the Federal Reserve policies and foreign demand for U.S. treasuries.

The quantitative results depend importantly on the assumed beliefs of the agents for the process driving foreign holdings. Since this process is estimated from the data as being very persistent, agents expect debt to stay constant in the future or mean-revert slowly. Instead, they are surprised over the period of analysis with larger than expected positive changes in foreign holdings. Allowing for learning on the law of motion of foreign holdings seems like an interesting avenue to extend this project.

Notwithstanding the caveats mentioned above, this model provides an explanation for the behavior of term premia and long-term yields that is consistent with the empirical evidence. Moreover, my results suggest that in the event of a reversal of flows, the term-premium would increase significatively, raising long-term yields. 


\section{References}

Abel, A. B. (1990): "Asset Prices Under Habit Formation and Catching Up With the Jones," American Economic Review, 80, 38-42.

Aguiar, M., And M. Amador (2011): "Growth in the Shadow of Expropriation*," The Quarterly journal of economics, 126(2), 651-697.

Alfaro, L., S. Kalemli-Ozcan, and V. Volosovych (2011): "Sovereigns, Upstream Capital Flows and Global Imbalances," NBER Working Papers 17396.

(2014): "Sovereigns, Upstream Capital Flows and Global Imbalances," Journal of the European Economic Association, 12(5), 1240-1284.

Angeletos, G.-M., and V. Panousi (2011): "Financial integration, entrepreneurial risk and global dynamics," Journal of Economic Theory, 146(3), 863-896.

Arellano, C., and A. Ramanarayanan (2012): "Default and the Maturity Structure in Sovereign Bonds," Journal of Political Economy, 120(2), 187-232.

Backus, D. K., A. W. Gregory, and S. E. Zin (1989): "Risk Premiums in the Term Structure: Evidence from Artificial Economies," Journal of Monetary Economics, 24, 371-399.

Backus, D. K., And J. H. Wright (2007): "Cracking the Conundrum," Brookings Papers on Economic Activity, 38(1), 293-329.

Bansal, R., And I. Shaliastovich (2012): "A Long-Run Risks Explanation of Predictability Puzzles in Bond and Currency Markets," Unpublished paper.

Beltran, D. O., M. Kretchmer, J. Marquez, and C. P. Thomas (2013): "Foreign holdings of U.S. Treasuries and U.S. Treasury yields," Journal of International Money and Finance, 32, $1120-1143$.

Bernanke, B. S. (2005): "The Global Savings Glut and the U.S. Current Account Deficit," Homer Jones Lecture, April 14, 2005. http://www. federalreserve.gov/boarddocs/speeches/2005/20050414/default.htm. 
(2006): Remarks by Governor Ben S. Bernanke at the Economic Club of New York, New York, New York, March 20, 2006.

Bernanke, B. S., C. Bertaut, L. P. Demarco, and S. Kamin (2011): "International Capital Flows and the Returns to Safe Assets in the United States, 2003-2007," Unpublished paper, International Finance Discussion Papers 1014, Board of Governors of the Federal Reserve System (U.S.).

Bernanke, B. S., V. R. Reinhart, and B. P. Sack (2004): "Monetary policy alternatives at the zero bound: an empirical assessment," Brookings Papers on Economic Activity, 35(2), $1-100$.

Bertaut, C. C., L. P. Demarco, S. Kamin, and R. W. Tryon (2011): "ABS Inflows to the United States and the Global Financial Crisis," International Finance Discussion Papers 1028. Board of Governors of the Federal Reserve System (U.S.).

Bertaut, C. C., and R. W. Tryon (2007): "Monthly Estimates of U.S. Cross-Border Securities Positions," International Finance Discussion Papers 910, Board of Governors of the Federal Reserve System (U.S.).

Caballero, R. J. (2006): "On the macroeconomics of asset shortages," National Bureau of Economic Research.

Caballero, R. J., E. Farhi, and P.-O. Gourinchas (2008): "An Equilibrium Model of "Global Imbalances" and Low Interest Rates," American Economic Review, 98(1), 358-393.

Caballero, R. J., and A. Krishnamurthy (2009): "Global Imbalances and Financial Fragility," The American Economic Review, pp. 584-588.

Campbell, J. Y., and J. H. Cochrane (1999): "By Force of Habit: A Consumption-Based Explanation of Aggregate Stock Market Behavior," Journal of Political Economy, 107, 205-251.

Campbell, J. Y., And R. J. Shiller (1991): "Yield Spreads and Interest Rates: A Bird's Eye View," Review of Economic Studies, 58, 495-514.

Cochrane, J. H., and M. Piazzesi (2005): "Bond Risk Premia," American Economic Review, 95(1), 138-160. 
(2008): "Decomposing the yield curve," Working Paper.

Constantinides, G. M. (1990): "Habit-formation: A Resolution of the Equity Premium Puzzle," Journal of Political Economy, 98, 519-543.

FAma, E. F., AND R. H. Bliss (1987): "The Information in Long-Maturity Forward Rates," American Economic Review, 77(4), 680-692.

Farhi, E., P.-O. Gourinchas, and H. Rey (2011): Reforming the International Monetary System. Centre for Economic Policy Research.

Favilukis, J., D. Kohn, S. C. Ludvigson, and S. Van Nieuwerburgh (2012): "International Capital Flows and House Prices: Theory and Evidence," in Housing and the Financial Crisis, ed. by E. L. Glaeser, and T. Sinai. University of Chicago Press, Chicago, IL.

Favilukis, J., S. C. Ludvigson, and S. Van Nieuwerburgh (2012a): "Foreign Ownership of U.S. Safe Assets: Good or Bad?," Unpublished paper, New York University.

(2012b): "The Macroeconomic Effects of Housing Wealth, Housing Finance and Limited Risk Sharing in General Equilibrium," Unpublished paper, New York University.

Ferson, W. E., and G. M. Constantinides (1991): "Habit Persistence and Durability in Aggregate Consumption," Journal of Financial Economics, 29, 199-240.

Gourinchas, P.-O., and O. Jeanne (2013): "Capital flows to developing countries: The allocation puzzle," The Review of Economic Studies, 1, 1-32.

Gourinchas, P.-O., And H. Rey (2013): "External Adjustment, Global Imbalances, Valuation Effects," Forthcoming, Chapter in Handbook in International Economics, vol IV, Gopinath, Helpman and Rogoff eds.

Greenspan, A. (2005): "Testimony of Chairman Alan Greenspan at the Federal Reserve Board's semiannual Monetary Policy Report to the Congress Before the Committee on Financial Services,", U.S. House of Representatives, July 20, 2005.

Gurkaynak, R. S., B. Sack, and J. H. Wright (2007): "The U.S. treasury yield curve: 1961 to the present," Journal of Monetary Economics, 54(8), 2291-2304. 
Gurkaynak, R. S., And J. H. Wright (2012): "Macroeconomics and the Term Structure," Journal of Economic Literature, 50(2), 331-367.

Hanson, S. G., and J. C. Stein (2014): "Monetary policy and long-term real rates," Journal of Financial Economics.

Hatchondo, J. C., And L. Martinez (2009): "Long-duration bonds and sovereign defaults," Journal of International Economics, 79(1), 117-125.

Heaton, J. (1995): "An Empirical Investigation of Asset Pricing with Temporally Dependent Preference Specifications," Econometrica, 63, 681-717.

Justiniano, A., G. Primiceri, and A. Tambalotti (2013): "The Effects of the Saving and Banking Glut on the U.S. Economy," Working Paper.

Kaminska, I., D. Vayanos, and G. Zinna (2011): "Preferred-habitat investors and the US term structure of real rates," .

Kaminska, I., And G. Zinna (2014): Official Demand for US Debt: Implications for US real interest rates, no. 14-66. International Monetary Fund.

Kim, D. H., And J. H. Wright (2005): “An Arbitrage-Free Three-Factor Term Structure Model and the Recent Behavior of Long-Term Yields and Distant-Horizon Forward Rates," FEDS Working Paper No. 2005-33.

Knotek II, E. S., And S. J. Terry (2010): "Markov-Chain Approximations of Vector Autoregressions: Application of General Multivariate-Normal Integration Techniques," Working Paper RWP 08-02, The Federal Reserve Bank of Kansas City.

Kohn, D. L. (2002): "Panel: Implications of Declining Treasury Debt. What Should the Federal Reserve Do as Treasury Debt Is Repaid?," Journal of Money, Credit and Banking, 34(3), 941-945.

LuCAS, R. E. (1990): "Why doesn't capital flow from rich to poor countries?," The American Economic Review, pp. 92-96.

Ludvigson, S. C., And S. NG (2009): "Macro Factors in Bond Risk Premia," The Review of Financial Studies, 22(12), 5027-5067. 
Maggiori, M. (2013): "Financial intermediation, international risk sharing, and reserve currencies," .

Mendoza, E. G., V. Quadrini, and J.-V. Rios-Rull (2009): "Financial Integration, Financial Development, and Global Imbalances," Journal of Political Economy, 117(3).

Obstfeld, M., and K. Rogoff (2010): "Global Imbalances and the Financial Crisis: Products of Common Causes," Asia Economic Policy Conference, pp. 131-173.

Piazzesi, M., And M. Schneider (2006): "Equilibrium Yield Curves," in NBER Macroeconomics Annual: 2006, ed. by M. W. Daron Acemoglu, Kenneth Rogoff. MIT Press, Cambridge.

Rudebusch, G., B. P. Sack, and E. T. Swanson (2007): "Macroeconomic Implications of Changes in the Term Premium," Federal Reserve Bank of St. Louis Review, 89(4).

Rudebusch, G., and E. Swanson (2008): "Examining the bond premium puzzle with a DSGE model," Journal of Monetary Economics, 55, S111-S126.

(2012): "The Bond Premium in a DSGE Model with Long-Run Real and Nominal Risks," American Economic Journal: Macroeconomics, 4(1), 105-143.

Rudebusch, G., E. Swanson, and T. Wu (2006): "The bond yield conundrum from a macrofinance perspective," Monetary and Economic Studies, 24(S1), 83109.

Sierra, J. (2010): "International Capital Flows and Bond Risk Premia," Bank of Canada, WP 2010-14.

SIERRA, JesUS, YEAR $=2014$, T. . I. J. . Q. V. . N. . . (????):.

Sundaresan, S. (1989): "Intertemporally Dependent Preferences and the Volatility of Consumption and Wealth," The Review of Financial Studies, 2, 73-89.

Swanson, E. (2007): "What We Do and Dont Know about the Term Premium," FRBSF ECONOMIC LETTER, (2007-21).

Tauchen, G. (1986): "Finite State Markov-Chain Approximations to Univariate and Vector Autoregressions," Economic Letters, 20, 177-181. 
TAYlor, J. B. (2007): "Housing and Monetary Policy," Remarks prepared for presentation at the Policy Panel at the Symposium on Housing, Housing Finance, and Monetary Policy in Jackson Hole, Wyoming.

VAyanos, D., And J.-L. Vila (2009): "A preferred-habitat model of the term structure of interest rates," National Bureau of Economic Research.

Wachter, J. (2006): "A Consumption Based Model of the Term Structure of Interest Rates," Journal of Financial Economics, 79, 365-399.

Warnock, F. E., And V. C. WARnock (2009): "International capital flows and U.S. interest rates," Journal of International Money and Finance, 28, 903-919.

Weil, P. (1989): "The Equity Premium Puzzle and the Risk-Free Rate Puzzle," Journal of Monetary Economics, 24(3), 401-421. 


\section{Appendix}

In this appendix, I show some algebraic derivations, and include empirical evidence on the behavior of foreign holdings over the last two decades and their effects on long-term bond yields.

The first subsection presents the derivation of the natural debt limit in the agent's problem above Equation 7). This debt limit is not binding in my solution. However, it is still needed to obtain this solution since without it the agent would increase its consumption and debt unboundedly.

The second subsection shows how $\delta$, the geometric rate of decline of the coupons in a long-term bond, is calibrated so that the duration of the long-term bond in the model matches the weighted average maturity of foreign holdings of U.S. Treasuries.

The third subsection presents the estimation procedure for the stochastic process governing the behavior of the exogenous state variables in the model (Equation 9). I estimate this process using a method of moments, which in this case is equivalent to OLS estimation.

The next three subsections provide empirical evidence on the behavior of foreign holdings of U.S. Treasuries during the last two decades. Subsection 5.4 presents the data sources, and subsection 5.5 describes some stylized facts about foreign holdings of U.S. Treasuries. Finally, subsection 5.6 presents empirical evidence on the effects of U.S. Treasury purchases by foreigners on long-term bonds realized excess returns. This evidence is similar to what recent empirical papers have found 61 and its intention is to motivate the theoretical model and quantitative findings in my paper.

\subsection{Natural Debt Limit}

Define the natural debt limit at $t$ as the maximum amount that is feasible to repay given $C_{t+i}=0 \forall i \geq 0$, no new purchases of long-term debt (just rollover the existing long-term debt), and no new purchases of short-term debt, for any history of shocks. Then,

$$
\widetilde{b}_{t}=\min \left\{\widetilde{b}_{t}^{s}, \widetilde{b}_{t}^{L}\right\}
$$

\footnotetext{
${ }^{61}$ See for example Beltran, Kretchmer, Marquez, and Thomas (2013) and Sierra (2010).
} 
where,

$$
\begin{aligned}
& \widetilde{b}_{t}^{s}=-\sum_{i=0}^{\infty}\left(\Pi_{j=1}^{i} \frac{1}{R_{t+j}^{s}}\right) Y_{t+i} \\
& \widetilde{b}_{t}^{L}=-\sum_{i=0}^{\infty}\left(\Pi_{j=1}^{i} \frac{1}{R_{t+j}^{L}}\right) \frac{Y_{t+i}}{1+\delta q_{t+i}^{L}}
\end{aligned}
$$

\section{$\underline{\text { Proof }}$}

The budget constraint of the agent's problem is:

$$
\begin{aligned}
C_{t} P_{t}+q_{t}^{s} B_{t}^{S}+q_{t}^{L} L_{t} & =P_{t} Y_{t}+B_{t-1}^{S}+B_{t-1}^{L} \\
B_{t}^{L} & =\delta B_{t-1}^{L}+L_{t} \\
& \Rightarrow \\
C_{t} P_{t}+q_{t}^{s} B_{t}^{S}+q_{t}^{L} B_{t}^{L} & =P_{t} Y_{t}+B_{t-1}^{S}+B_{t-1}^{L}\left(1+\delta q_{t}^{L}\right)
\end{aligned}
$$

where $B_{t}^{S}$ is the quantity, chosen at $t$, of a short-term bond that promises one unit of $\$$ at $t+1$, and $B_{t}^{L}$ is the quantity, chosen at $t$, of a long-term bond that promises a stream of declining coupons of $\$$ at $t+i \forall i$, with geometric rate of decline $\delta$.

This equation can be rewritten in real terms,

$$
\begin{aligned}
C_{t}+q_{t}^{s} \frac{B_{t}^{S}}{P_{t}}+q_{t}^{L} \frac{B_{t}^{L}}{P_{t}} & =Y_{t}+\frac{B_{t-1}^{S}}{P_{t}}+\frac{B_{t-1}^{L}}{P_{t}}\left(1+\delta q_{t}^{L}\right) \\
C_{t}+q_{t}^{S}\left(1+\pi_{t+1}\right) b_{t+1}^{s}+q_{t}^{L}\left(1+\pi_{t+1}\right) b_{t+1}^{L} & =Y_{t}+b_{t}^{s}+b_{t}^{L}\left(1+\delta q_{t}^{L}\right)
\end{aligned}
$$

We are looking for the weakest borrowing limit that needs to be satisfied in order for the agent to be able to repay his debt: i.e., the "natural borrowing limit".

Assume $C_{t+i}=0 \forall i \geq 0$. Also assume one of the following:

(i) $b_{t+1+i}^{L}=\frac{\delta}{1+\pi_{t+1+i}} b_{t+i}^{L} \forall i \geq 0$, no new purchases of long-term debt $\left(L_{t+i}=0 \forall i \geq 0\right)$, just rollover the existing long-term debt. Or,

(ii) $b_{t+1+i}^{s}=0 \forall i \geq 0$, no new purchases of short-term debt.

Using (i) and $C_{t+i}=0, \forall i \geq 0$, 


$$
\begin{aligned}
b_{t}^{s}+b_{t}^{L}\left(1+q_{t}^{L}\right) & =-Y_{t}+q_{t}^{S}\left(1+\pi_{t+1}\right) b_{t+1}^{s}+q_{t}^{L}\left(1+\pi_{t+1}\right) b_{t+1}^{L} \\
b_{t+1}^{L} & =\frac{\delta}{1+\pi_{t+1}} b_{t}^{L} \\
\Rightarrow & \\
b_{t}^{s} & =-Y_{t}-b_{t}^{L}+q_{t}^{S}\left(1+\pi_{t+1}\right) b_{t+1}^{s}
\end{aligned}
$$

Iterating forward on the budget constraint above, we get:

$$
\begin{aligned}
& b_{t}^{s}=-\sum_{i=0}^{\infty}\left(\Pi_{j=1}^{i} \frac{1}{R_{t+j}^{s}}\right)\left(Y_{t+i}+b_{t+i}^{L}\right) \\
& b_{t}^{s}=-\sum_{i=0}^{\infty}\left(\Pi_{j=1}^{i} \frac{1}{R_{t+j}^{s}}\right) Y_{t+i}-b_{t}^{L} \sum_{i=0}^{\infty} \delta^{i}\left(\Pi_{j=1}^{i} \frac{1}{1+y_{t+j}^{S}}\right)
\end{aligned}
$$

where we imposed the transversality conditions:

$$
\begin{array}{r}
\lim _{n \rightarrow \infty}\left(\Pi_{j=1}^{i} \frac{1}{R_{t+n}^{S}}\right) b_{t+n}^{s}=0 \\
\lim _{n \rightarrow \infty}\left(\Pi_{j=1}^{i} \frac{1}{1+y_{t+n}^{S}}\right) b_{t+n}^{L}=0
\end{array}
$$

Also we used $q_{t}^{S} \equiv \frac{1}{R_{t+1}^{S}}$, and $1+y_{t+1}^{S} \equiv R_{t+1}^{S}\left(1+\pi_{t+1}\right)$.

Define the present value of long-term debt, as $P V\left(b_{t}^{L}\right) \equiv \sum_{i=0}^{\infty} \delta^{i}\left(\Pi_{j=1}^{i} \frac{1}{1+y_{t+j}^{S}}\right)$ and the natural debt limit on short-term debt as $\widetilde{b}_{t}^{s} \equiv-\sum_{i=0}^{\infty}\left(\Pi_{j=1}^{i} \frac{1}{R_{t+j}^{S}}\right) Y_{t+i}$. Then we get the following constraint for every $t$,

$$
b_{t}^{s}+b_{t}^{L} P V\left(b_{t}^{L}\right) \geq \widetilde{b}_{t}^{s}
$$

Now, using (ii) and $C_{t+i}=0 \forall i \geq 0$, and iterating forward on long-term debt:

$$
b_{t}^{s}+b_{t}^{L}=-\sum_{i=0}^{\infty}\left(\Pi_{j=1}^{i} \frac{1}{R_{t+j}^{L}}\right) \frac{Y_{t+i}}{1+\delta q_{t+1}^{L}}
$$


where $R_{t+1}^{L} \equiv \frac{\frac{1+\delta q_{t}^{L}}{q_{t}^{L}}}{1+\pi_{t+1}}$. Define the natural debt limit on long-term debt as $\widetilde{b}_{t}^{L} \equiv-\sum_{i=0}^{\infty}\left(\Pi_{j=1}^{i} \frac{1}{R_{t+j}^{L}}\right) \frac{Y_{t+i}}{1+\delta q_{t+1}^{L}}$. Then we get the following constraint for every $t$,

$$
b_{t}^{s}+b_{t}^{L} \geq \widetilde{b}_{t}^{L}
$$

We can thus define the natural debt limit as,

$$
\widetilde{b}_{t}=\min \left\{\widetilde{b}_{t}^{s}, \widetilde{b}_{t}^{L}\right\}
$$

We can express this debt limit as a limit for the ratio of debt to income. Take the case (i) above:

$$
\begin{aligned}
b_{t}^{s}+b_{t}^{L} P V\left(b_{t}^{L}\right) & \geq \widetilde{b}_{t}^{s} \\
& \geq-\sum_{i=0}^{\infty}\left(\Pi_{j=1}^{i} \frac{1}{R_{t+j}^{S}}\right) Y_{t+i} \\
& \geq-Y_{t} \sum_{i=0}^{\infty}\left(\Pi_{j=1}^{i} \frac{1+\rho_{t+j}}{R_{t+j}^{S}}\right) \\
\frac{b_{t}^{s}+b_{t}^{L} P V\left(b_{t}^{L}\right)}{Y_{t}} & \geq-\sum_{i=0}^{\infty}\left(\Pi_{j=1}^{i} \frac{1+\rho_{t+j}}{R_{t+j}^{S}}\right)
\end{aligned}
$$

where $\rho_{t+j}=\frac{Y_{t+j}}{Y_{t+j-1}}-1$.

\subsection{How $\delta$ affects duration}

$\delta$, the rate of decline of coupons for a perpetuity in the model, can be calibrated to match the duration of any long-term zero-coupon bond, which makes this perpetuity an attractive substitute for modeling purposes. In this subsection I describe this calibration.

The MacCaulay Duration (the weighted average maturity of cash flows) of a long-term bond in 
the model is given by,

$$
\begin{aligned}
M a c D & =\frac{\sum_{i=1}^{\infty} i \delta^{i-1} e^{-y_{t} i}}{q_{t}^{L}} \\
M a c D & =\frac{1}{1-\frac{\delta}{e^{y_{t}}}}
\end{aligned}
$$

The duration increases with $\delta$ for a given yield and decreases with the yield, for a given $\delta$. Given the yield and duration, I can compute $\delta$ as:

$$
\delta=\frac{M a c D-1}{M a c D} e^{y_{t}}
$$

Notice that $\delta=0$ for a one-period bond $(M a c D=1)$.

\subsection{Estimating a VAR in the data}

Endowment growth, foreign holdings over endowment, and inflation follow exogenous VAR(1) process:

$$
\begin{aligned}
X_{t} & =(I-A) \mu+A X_{t-1}+\epsilon_{t} \\
& =A 0+A X_{t-1}+\epsilon_{t} \\
X_{t} & \equiv\left(\begin{array}{c}
\Delta y_{t} \\
f_{t} \\
\pi_{t}
\end{array}\right), \epsilon_{t} \equiv\left(\begin{array}{c}
\epsilon_{t}^{\Delta y} \\
\epsilon_{t}^{f} \\
\epsilon_{t}^{\pi}
\end{array}\right)
\end{aligned}
$$

where $\Delta y_{t} \equiv \log \left(\frac{Y_{t}}{Y_{t-1}}\right), f_{t} \equiv \frac{F_{t}}{P_{t} Y_{t}}, \pi_{t} \equiv \log \left(\frac{P_{t}}{P_{t-1}}\right), A$ and $\Sigma$ are $3 x 3$.

I estimate this VAR by method of moments ${ }^{62}$ I have 18 parameters: 9 coefficients of $\mathrm{A}, 6$ for $\Sigma$ (symmetric), and 3 for $\mu$. I use the following 18 moments to match these parameters:

$\mu_{\Delta y}, \mu_{f}, \mu_{\pi}, \sigma_{\Delta y}, \sigma_{f}, \sigma_{\pi}, \rho(1)_{\Delta y}, \rho(1)_{f}, \rho(1)_{\pi}, \operatorname{Cov}(\Delta y, f), \operatorname{Cov}(\Delta y, \pi), \operatorname{Cov}(\pi, f)$,

$\operatorname{Cov}\left(\Delta y^{\prime}, f\right), \operatorname{Cov}\left(\Delta y^{\prime}, \pi\right), \operatorname{Cov}\left(\pi^{\prime}, \Delta y\right), \operatorname{Cov}\left(\pi^{\prime}, f\right), \operatorname{Cov}\left(f^{\prime}, \pi\right), \operatorname{Cov}\left(f^{\prime}, \Delta y\right)$.

${ }^{62}$ The resulting equations defining the parameters are the same as in OLS, so the estimated coefficients are same under both methods, if I use the same sample moments. 
$A$ can be estimated from the following 9 equations, using sample moments:

$$
\begin{gathered}
\operatorname{Cov}\left(\Delta y^{\prime}, \Delta y\right)=a_{11} \operatorname{Var}(\Delta y)+a_{12} \operatorname{Cov}(\Delta y, f)+a_{13} \operatorname{Cov}(\Delta y, \pi) \\
\operatorname{Cov}\left(\Delta y^{\prime}, f\right)=a_{11} \operatorname{Cov}(f, \Delta y)+a_{12} \operatorname{Var}(f)+a_{13} \operatorname{Cov}(f, \pi) \\
\operatorname{Cov}\left(\Delta y^{\prime}, \pi\right)=a_{11} \operatorname{Cov}(\pi, \Delta y)+a_{12} \operatorname{Cov}(\pi, f)+a_{13} \operatorname{Var}(\pi) \\
\operatorname{Cov}\left(f^{\prime}, \Delta y\right)=a_{21} \operatorname{Var}(\Delta y)+a_{22} \operatorname{Cov}(\Delta y, f)+a_{23} \operatorname{Cov}(\Delta y, \pi) \\
\operatorname{Cov}\left(f^{\prime}, f\right)=a_{21} \operatorname{Cov}(f, \Delta y)+a_{22} \operatorname{Var}(f)+a_{23} \operatorname{Cov}(f, \pi) \\
\operatorname{Cov}\left(f^{\prime}, \pi\right)=a_{21} \operatorname{Cov}(\pi, \Delta y)+a_{22} \operatorname{Cov}(\pi, f)+a_{23} \operatorname{Var}(\pi) \\
\operatorname{Cov}\left(\pi^{\prime}, \Delta y\right)=a_{31} \operatorname{Var}(\Delta y)+a_{32} \operatorname{Cov}(\Delta y, f)+a_{33} \operatorname{Cov}(\Delta y, \pi) \\
\operatorname{Cov}\left(\pi^{\prime}, f\right)=a_{31} \operatorname{Cov}(f, \Delta y)+a_{32} \operatorname{Var}(f)+a_{33} \operatorname{Cov}(f, \pi) \\
\operatorname{Cov}\left(\pi^{\prime}, \pi\right)=a_{31} \operatorname{Cov}(\pi, \Delta y)+a_{32} \operatorname{Cov}(\pi, f)+a_{33} \operatorname{Var}(\pi)
\end{gathered}
$$

In matrix notation:

$$
\begin{aligned}
& A C=B \\
& A=B * C^{-1}
\end{aligned}
$$

where,

$$
B=\left(\begin{array}{ccc}
\operatorname{Cov}\left(\Delta y^{\prime}, \Delta y\right) & \operatorname{Cov}\left(\Delta y^{\prime}, f\right) & \operatorname{Cov}\left(\Delta y^{\prime}, \pi\right) \\
\operatorname{Cov}\left(f^{\prime}, \Delta y\right) & \operatorname{Cov}\left(f^{\prime}, f\right) & \operatorname{Cov}\left(f^{\prime}, \pi\right) \\
\operatorname{Cov}\left(\pi^{\prime}, \Delta y\right) & \operatorname{Cov}\left(\pi^{\prime}, f\right) & \operatorname{Cov}\left(\pi^{\prime}, \pi\right)
\end{array}\right)
$$

and,

$$
C=\left(\begin{array}{ccc}
\operatorname{Var}(\Delta y) & \operatorname{Cov}(f, \Delta y) & \operatorname{Cov}(\pi, \Delta y) \\
\operatorname{Cov}(\Delta y, f) & \operatorname{Var}(f) & \operatorname{Cov}(\pi, f) \\
\operatorname{Cov}(\Delta y, \pi) & \operatorname{Cov}(f, \pi) & \operatorname{Var}(\pi)
\end{array}\right)
$$

Solution is unique as long as $\mathrm{C}$ is invertible.

Then, I can solve for A0:

$$
A 0=(I-A)^{-1} \mu
$$


Table 6: Estimation 1952Q1-2006Q4, target sample moments

\begin{tabular}{ccc} 
Process for $\Delta y, q x f$ and $\pi$, 1952Q1-2006Q4 \\
\hline$\mu_{\Delta y}$ & $0.47 \%$ & Mean endowment growth \\
$\sigma_{\Delta y}$ & $0.51 \%$ & Std endowment growth \\
$\mu_{\pi}$ & $0.93 \%$ & Mean Inflation \\
$\sigma_{\pi}$ & $0.75 \%$ & Std Inflation \\
$\mu_{q x f}$ & $4.00 \%$ & Mean foreign holdings over GDP \\
$\sigma_{q x f}$ & $2.54 \%$ & Std foreign holdings over GDP \\
$\rho_{\Delta y^{\prime}, \Delta y}$ & 0.17 & AR(1) endowment growth \\
$\rho_{\Delta y^{\prime}, f}$ & -0.07 & Correlation $\Delta y^{\prime}$ and $f$ \\
$\rho_{\Delta y^{\prime}, \pi}$ & -0.16 & Correlation $\Delta y^{\prime}$ and $\pi$ \\
$\rho_{f^{\prime}, f}$ & 0.997 & AR(1) foreign holdings over GDP \\
$\rho_{f^{\prime}, \Delta y}$ & -0.10 & Correlation $f^{\prime}$ and $\Delta y$ \\
$\rho_{f^{\prime}, \pi}$ & 0.07 & Correlation $f^{\prime}$ and $\pi$ \\
$\rho_{\pi^{\prime}, \pi}$ & 0.83 & AR(1) Inflation \\
$\rho_{\pi^{\prime}, \Delta y}$ & -0.07 & Correlation $\pi^{\prime}$ and $\Delta y$ \\
$\rho_{\pi^{\prime}, f}$ & 0.06 & Correlation $\pi^{\prime}$ and $f$ \\
$\rho_{\Delta y, \pi}$ & -0.24 & Correlation $\Delta y$ and $\pi$ \\
$\rho_{f, \Delta y}$ & -0.07 & Correlation $f_{t}$ and $\Delta y$ \\
$\rho_{f, \pi}$ & 0.05 & Correlation $f_{t}$ and $\pi$
\end{tabular}

Notes: Sample moments for 1952Q1-2006Q4. $\Delta y$ is consumption growth, where consumption is real per capita consumption of nondurables and services minus the change in current account deficit over GDP. $f_{t}$ is stock of foreign holdings of US Treasury bills, bonds and notes, over nominal trend GDP. $\pi$ is CPI price inflation. Data on foreign holdings of US Treasuries from Flow of Funds, Federal Reserve. Other data from BEA. Mean and Std for $q x f$ are divided by $K=0.224$. See below for explanation on this adjustment.

Finally I solve for 6 parameters in $\Sigma$, which is symmetric $\left(\sigma_{12}=\sigma_{21}, \sigma_{13}=\sigma_{31}, \sigma_{32}=\sigma_{23}\right)$, using 6 moments: $\operatorname{Var}(\Delta y), \operatorname{Var}(f), \operatorname{Var}(\pi), \operatorname{Cov}(\Delta y, f), \operatorname{Cov}(\Delta y, \pi), \operatorname{Cov}(\pi, f)$.

$$
\begin{aligned}
\sigma_{11}= & \left(1-a_{11}^{2}\right) \operatorname{Var}(\Delta y)-a_{12}^{2} \operatorname{Var}(f)-a_{13}^{2} \operatorname{Var}(\pi)-2 a_{11} a_{12} \operatorname{Cov}(\Delta y, f)-2 a_{11} a_{13} \operatorname{Cov}(\Delta y, \pi)-2 a_{12} a_{13} \operatorname{Cov}(f, \pi) \\
\sigma_{22}= & -a_{21}^{2} \operatorname{Var}(\Delta y)+\left(1-a_{22}^{2}\right) \operatorname{Var}(f)-a_{23}^{2} \operatorname{Var}(\pi)-2 a_{21} a_{22} \operatorname{Cov}(\Delta y, f)-2 a_{21} a_{23} \operatorname{Cov}(\Delta y, \pi)-2 a_{22} a_{23} \operatorname{Cov}(f, \pi) \\
\sigma_{33}= & -a_{31}^{2} \operatorname{Var}(\Delta y)+-a_{32}^{2} \operatorname{Var}(f)+\left(1-a_{33}^{2}\right) \operatorname{Var}(\pi)-2 a_{31} a_{32} \operatorname{Cov}(\Delta y, f)-2 a_{31} a_{33} \operatorname{Cov}(\Delta y, \pi)-2 a_{32} a_{33} \operatorname{Cov}(f, \pi) \\
\sigma_{12}= & -a_{11} a_{21} \operatorname{Var}(\Delta y)-a_{12} a_{22} \operatorname{Var}(f)-a_{13} a_{23} \operatorname{Var}(\pi)+ \\
& +\left(1-a_{11} a_{22}-a_{12} a_{21}\right) \operatorname{Cov}(\Delta y, f)-\left(a_{13} a_{21}+a_{11} a_{23}\right) \operatorname{Cov}(\Delta y, \pi)-\left(a_{12} a_{23}+a_{13} a_{22}\right) \operatorname{Cov}(f, \pi) \\
\sigma_{13}= & -a_{11} a_{31} \operatorname{Var}(\Delta y)-a_{12} a_{32} \operatorname{Var}(f)-a_{13} a_{33} \operatorname{Var}(\pi)- \\
& -\left(a_{11} a_{32}+a_{12} a_{31}\right) \operatorname{Cov}(\Delta y, f)+\left(1-a_{13} a_{31}-a_{11} a_{33}\right) \operatorname{Cov}(\Delta y, \pi)-\left(a_{12} a_{33}+a_{13} a_{32}\right) \operatorname{Cov}(f, \pi) \\
\sigma_{23}= & -a_{21} a_{31} \operatorname{Var}(\Delta y)-a_{22} a_{32} \operatorname{Var}(f)-a_{23} a_{33} \operatorname{Var}(\pi)- \\
& -\left(a_{21} a_{32}+a_{22} a_{31}\right) \operatorname{Cov}(\Delta y, f)-\left(a_{23} a_{31}-a_{21} a_{33}\right) \operatorname{Cov}(\Delta y, \pi)+\left(1-a_{22} a_{33}-a_{23} a_{32}\right) \operatorname{Cov}(f, \pi)
\end{aligned}
$$

This process is estimated to match the target moments presented in Table 6 . 


\subsection{Data Overview}

In this section I review the data sources for foreign purchases of U.S. Treasury bonds. While the primary source of data is the Treasury International Capital reporting system, the Federal Reserve adjusts this data for known biases and valuation adjustments, to produce the Flow of Funds. In the following subsection, I present stylized facts based on the Flow of Funds data, which is the source I used to estimate the model. The last subsection presents empirical evidence on the impact of foreign purchases on Treasury yields.

\section{Data sources $\underline{\text { TIC data }}$}

The Treasury International Capital (TIC) reporting system provides data on both transactions and holdings of U.S. securities by non-US residents. The system provides monthly data on transactions and holdings of short-term and long-term securities 63 and annual detailed positions data on holdings of long-term and short-term securities ${ }^{64}$

Monthly transactions data are reported by brokers/dealers of securities, banks, and other market participants (financial intermediaries, not end-use investors) with a six week lag and provide data on cross-border transactions in U.S. Treasuries, U.S. agencies, U.S. corporate bonds and stocks, and foreign bonds and stocks. The annual detailed positions data are reported by U.S. custodians of securities, issuers of U.S. securities in foreign countries, and U.S. investors in foreign countries (custodians and other large end-use investors). The annual surveys are considered very accurate, although their results come with a 10-month lag. These surveys are available yearly from 2002, and before that for the years 1974, 1978, 1984, 1989, 1994, and 2000. The annual surveys are designed to cover about 90 percent of the universe of positions.

Attribution between countries and between private and official sources in the annual holdings surveys are imperfect, because some foreign owners entrust the safekeeping of their securities to institutions that are neither in the United States nor in the owner's country of residence. This problem is known as "custodial bias". In addition to the shortcomings of the positions data, transactions data induces an extra source of error in the country allocation, and may cause an underestimation of the official holdings, if a Foreign Official Institution chooses to buy securities through a private institution. This is known as "transaction bias".

\footnotetext{
${ }^{63}$ Monthly holdings data for long-term securities are very recent, and do not extend further back in time.

${ }^{64}$ See http://www.treasury.gov/resource-center/data-chart-center/tic/Pages/index . aspx
} 
Since TIC data is available monthly, I use these data for the monthly regressions in the last subsection of this appendix. Furthermore, these data have been widely used in previous studies, so it allows for a more direct comparison with the previous empirical literature.

Flow of Funds data

The Federal Reserve produces the Flow of Funds (FoF) accounts of the United States. This is a set of aggregate integrated financial accounts that measures sources and uses of funds for the economy as a whole, and by sector. It has the advantage that it allows the decomposition of the total stock of U.S. Treasuries and safe assets by holder in a coherent way.

FoF data on foreign security holdings and flows use as input the data published by the Bureau of Economic Analysis (BEA), in its international transactions accounts, which are based on data from the TIC system. Data reported on the TIC transactions accounts are adjusted by BEA to account for systematic and known under- or overestimates of reported transactions, based largely on the annual surveys, and for valuation adjustments. I use these data, which are "survey consistent", for the ../Figures below and for the estimation in the quantitative section.

In FoF data, short-term (less than one-year maturity) and long-term maturity securities are pooled together. Estimates of net foreign purchases are based on the monthly transactions data on gross purchases and sales by TIC, which are reported at market prices as of the settlement date. First, gross sales and purchases are adjusted for implicit commissions, and for expected misreporting in the transactions data. BEA adjusts the gross sales of Treasury bonds by private foreigners, and does offsetting adjustments to increase net purchases of Treasury bonds by foreign official institutions to correct for the "transactions bias" explained above 65

Foreign Official Agencies are defined as Treasuries, including ministries of finance, central banks, and stabilization funds, exchange control offices, or other governmental exchange authorities. Also included are private banks or corporations that act as fiscal agents of national governments. The term "Foreign Official Institutions" used in TIC reports differs from the "Foreign Official Agencies" used by BEA, in that the former includes international and regional organizations, excluded in the latter one. In this paper I refer to any of these two concepts indistinctively as Foreign Official Institutions.

As a result of the adjustments described above, while BEA and TIC series for total foreign

\footnotetext{
${ }^{65}$ For a more detailed description see U.S. International Transactions Accounts Concepts and Estimation Methods, BEA, June 2011, in particular pages 105-107 and 121-125.
} 
holdings and flows resemble closely, holdings by Foreign Official Institutions are very different.

\subsection{Empirical evidence on foreign holdings of U.S. Treasury securities}

In this subsection I present some suggestive evidence on the importance of net purchases of U.S. Treasuries and Government-backed Agency debt by foreigners, and Foreign Official Institutions in particular. I use data from the Flow of Funds in this section, given the discussion above. These data include both short-term Treasury bills and long-term Treasury securities.

The first stylized fact I present here highlights the economic relevance of my question. Figure 16 presents total foreign holdings of U.S. Treasury bills, bonds and notes, by holder 66 This figure shows that U.S. Treasuries holdings (and purchases) by foreigners are economically significant, both in terms of GDP and out of total U.S. Treasuries outstanding.

Figure 16: UST holdings by holder
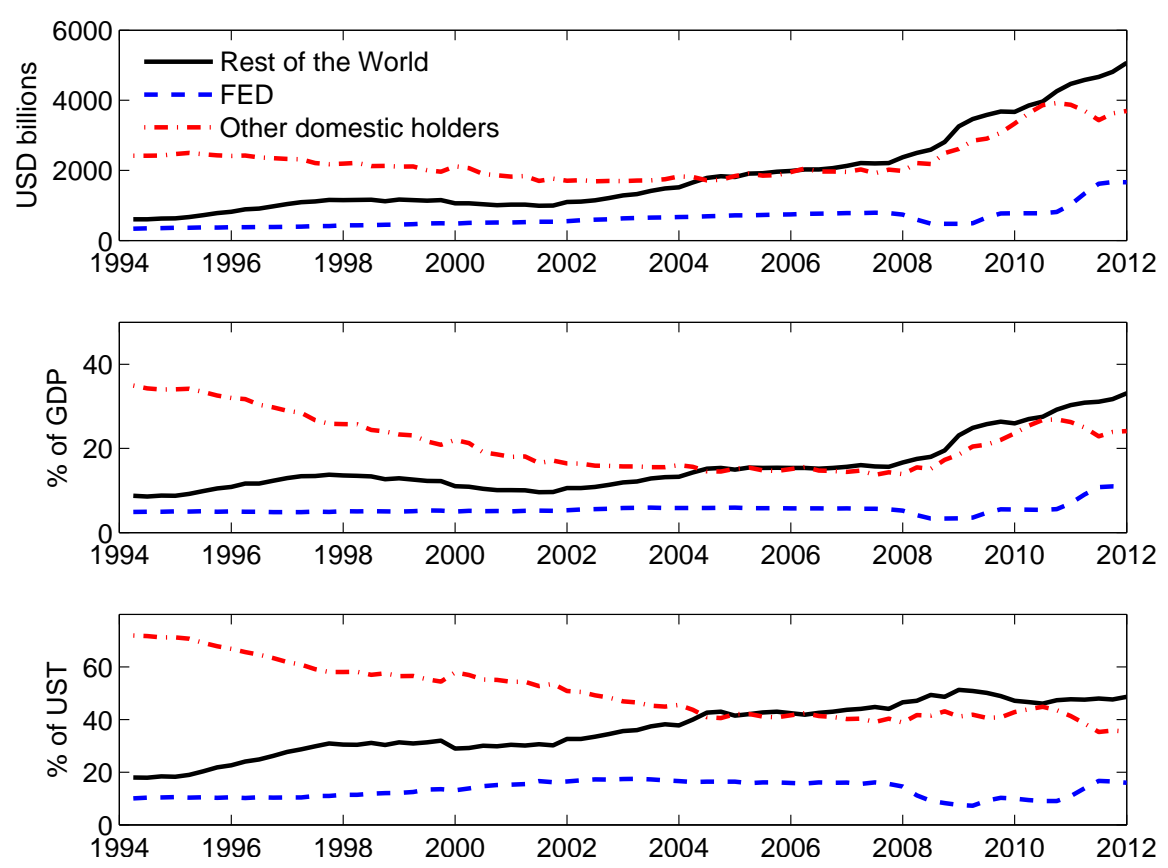

As shown in the figure above, U.S. treasuries purchases by Foreign Official Institutions became quantitatively significant over the last two decades. From 1994Q1 to 2011Q4, the total amount of UST held by foreigners increased from $\$ 0.6 \operatorname{trn}(8.8 \%$ of GDP) to $\$ 5.1 \operatorname{trn}(33.1 \%$ of GDP). Moreover, the change in foreigners holdings represented $63.2 \%$ of the change in total U.S. Treasuries outstanding over this period, rising from $18 \%$ to $48.6 \%$ of total UST outstanding. Considering both

\footnotetext{
${ }^{66}$ Other domestic includes every sector other than the FED and the Rest of the World.
} 
UST and Agencies (Agency- and Government Sponsored Enterprises- backed securities), over this same period, while the total amount of these securities increased from $77.4 \%$ to $117.5 \%$ of GDP, foreign holdings increased from $10.3 \%$ to $40.1 \%$ of GDP 67

These inflows to safe assets have helped financing both the recent U.S. current account deficit and the government deficit. The upward trend in the current account deficit has coincided by an upward trend in net flows of securities. Among these, the net foreign holdings of risky assets have fluctuated around zero (Favilukis, Kohn, Ludvigson, and Van Nieuwerburgh 2012), so net foreign holdings of U.S. safe assets correspond closely in magnitude and evolution to the current account deficit in the U.S. Figure 17 shows that U.S. Treasuries net purchases by FOI have moved closely with the growing current account deficit of recent years.

Figure 17: UST purchases by FOI and CA deficit

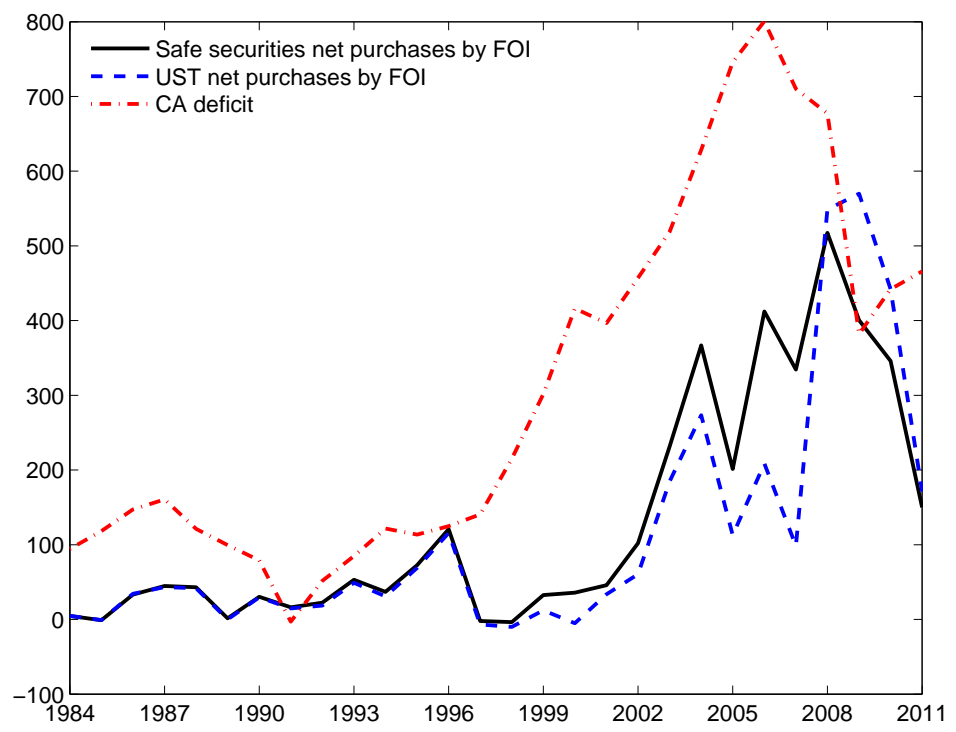

Most of this large increase in foreign holdings of safe assets was due to Foreign Official Institutions (FOI) purchases. FOI holdings of UST increased from $5.4 \%$ to $23.8 \%$ of GDP (5.5\% to $28.1 \%$ for UST plus Agencies). In 2011Q4 they represented $72 \%$ of total foreign holdings, and over the period 1994Q1-2011Q4 they accounted for 73.4\% of the increase in total foreign holdings of UST, and for $46.4 \%$ of the increase in total UST. Figure 18 presents the evolution of the ownership composition of foreigners holdings during this period.

\footnotetext{
${ }^{67}$ Data from Flow of Funds, based on surveys conducted by Treasury International Capital (TIC) reporting system.
} 
Figure 18: UST holdings by Rest of the World

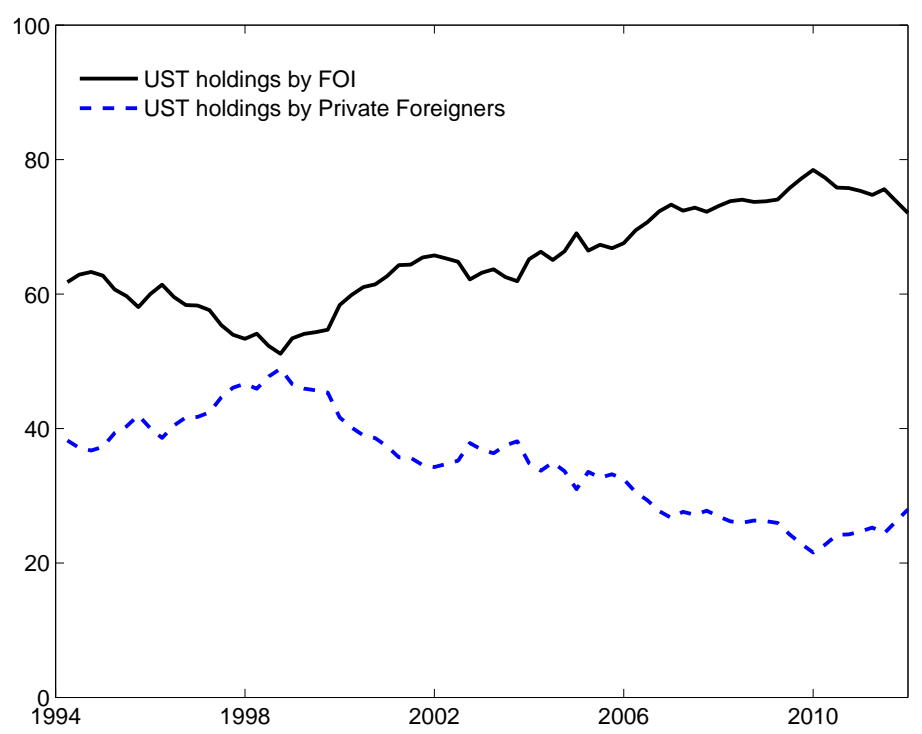

Maturity composition of foreign holdings Table 7 presents the maturity structure of US Treasury holdings by foreign official institutions. As can be seen in the table below, $72.4 \%$ of the total long-term US treasuries had up to 5 years remaining to maturity, at June 2012. Long-term Treasury securities, those that mature in one year or more, represented $91 \%$ of the total UST holdings by FOI. And the weighted average maturity of these holdings was 4.2 years for long-term bonds, and 3.8 years when including short-term Treasury bills.

Table 7: US Treasuries holdings by FOI, maturity, at June 2012

Panel A: ST and LT US Treasuries by FOI

ST Treas. $(<1 \mathrm{yr}) \quad \$ 366 \mathrm{~B} . \quad 9 \%$

LT Treas. $\quad \$ 3,489 \mathrm{~B} . \quad 91 \%$

Panel B: LT US Treasuries by FOI, remaining yrs to Mat.

Up to 5

$72.4 \%$

5 to 10

$24.1 \%$

More than 5

$3.5 \%$

WAM of LT Treas

$4.2 \mathrm{yrs}$

WAM including ST Treas

$3.8 \mathrm{yrs}$

Notes: WAM is weighted average maturity. Short-term debt (original) maturity of one year or less. Maturity Structure of Foreign Holdings of US Long-Term Debt Securities as of June 2012, Table 17b, TIC system data. 


\subsection{Empirical Analysis: foreign purchases and realized excess returns}

In this section I conduct an empirical investigation in order to determine the effect of foreign official purchases of U.S. treasuries on long-term bond yields. In particular, I focus on their impact on realized excess returns. My estimations in this section are similar to the empirical exercises in Sierra (2010), and their purpose is to replicate the flavor of the results in previous papers.

Some useful notationLet $p_{t}^{(n)}$ be the log price of n-year zero-coupon bond at time t. The log yield is given by,

$$
y_{t}^{(n)}=-(1 / n) p_{t}^{(n)}
$$

The log holding period return is,

$$
r_{t+1}^{(n)}=p_{t+1}^{(n-1)}-p_{t}^{(n)}
$$

where the period could be either months, quarters or years.

The $\log$ forward rate is at time $\mathrm{t}$, for loans between $t+n-1$ and $t+n$ is,

$$
g_{t}^{(n)}=p_{t}^{(n-1)}-p_{t}^{(n)}
$$

Denote $r x_{t+1}^{(n)}$ the continuously compounded $(\log )$ excess return on an n-year discount bond in period $t+1$,

$$
r x_{t+1}^{(n)}=r_{t+1}^{(n)}-y_{t}^{(1)}
$$

where $r_{t+1}^{(n)}$ is the log holding period return from buying an n-year bond at time $t$ and selling it as an $n-1$ year bond at time $t+1 ; y_{t}^{(1)}$ is the log yield on the one-year bond.

Bond risk premia and foreign flows, some resultsI use a standard approach for assessing whether excess bond returns are predictable, that follows Ludvigson and Ng (2009), and estimate the regression below by OLS:

$$
r x_{t+1}^{(n)}=\gamma^{\prime} x_{t}+\beta^{\prime} Z_{t}+\epsilon_{t+1}
$$


where $x_{t}$ is a measure of foreign official net purchases of U.S. treasuries, and $Z_{t}$ is a vector of control variables that includes the single forward factor studied in Cochrane and Piazzesi (2005) (a linear combination of $y_{t}^{(1)}$ and four forward rates) and other macroeconomic variables.

Table 8 presents results for the regressions of holding period (log) excess returns for 1-year periods, for $n=2,3,4,5$, on 12 months cumulated net purchases of U.S. Treasury notes and bonds up to the beginning of the holding period, normalized by total marketable U.S. Treasury notes and bonds at that period. Observations are monthly and span from December 1994 to December 2010. The control variables are the Cochrane-Piazzesi factor (CP), the Chicago Fed National Activity Index (CFNAI), and the log change in the consumer price index $(\Delta \mathrm{CPI})$. I compare the forecasting power of these regressions excluding foreign purchases (Panel A, left column), and including foreign purchases (Panel B, right column).

The results in that table show that in all cases the presence of the net foreign purchases by FOI increases the $R^{2}$, although this variable is only statistically significative for $n=2$ and $n=3$. Moreover, the coefficient of the foreign flows variables in all cases is negative: net foreign purchases of U.S. Treasuries decrease the realized excess returns, even when they are lagged one year.

It is important to notice that these results are very sensitive to the chosen sample: they are stronger for 1994 to 2007, but for a longer sample from 1984 to 2010, I don't find a statistically significant increase in the forecasting power of excess returns by foreign flows. However, in all cases, foreign purchases by official institutions have a negative coefficient 68

Summarizing the evidence presented in this section, for the period December 1994 to December 2010, results suggest that foreign purchases of U.S. treasuries have a negative and significative effect on excess returns, above other control variables (at least for $n=2$ and $n=3$ ). They also increase the $R^{2}$ of the linear regression. These findings suggest that foreign flows reduce bonds returns risk premium (conditional mean) and increase excess returns predictability.

The evidence presented here is consistent with what other studies have found using an IV approach (i.e. Sierra (2010), Beltran, Kretchmer, Marquez, and Thomas (2013)), and intends to serve only as motivation for my model findings.

\footnotetext{
${ }^{68} \mathrm{I}$ also performed these regressions with alternative transformations of the data, with quarterly data, and with other definitions for foreign purchases: adjusting flows using data by Bertaut and Tryon (2007), with and without valuation changes, using monthly flows, and including short-term treasuries.
} 
Table 8: Monthly Regressions, Dec1994-Dec2010

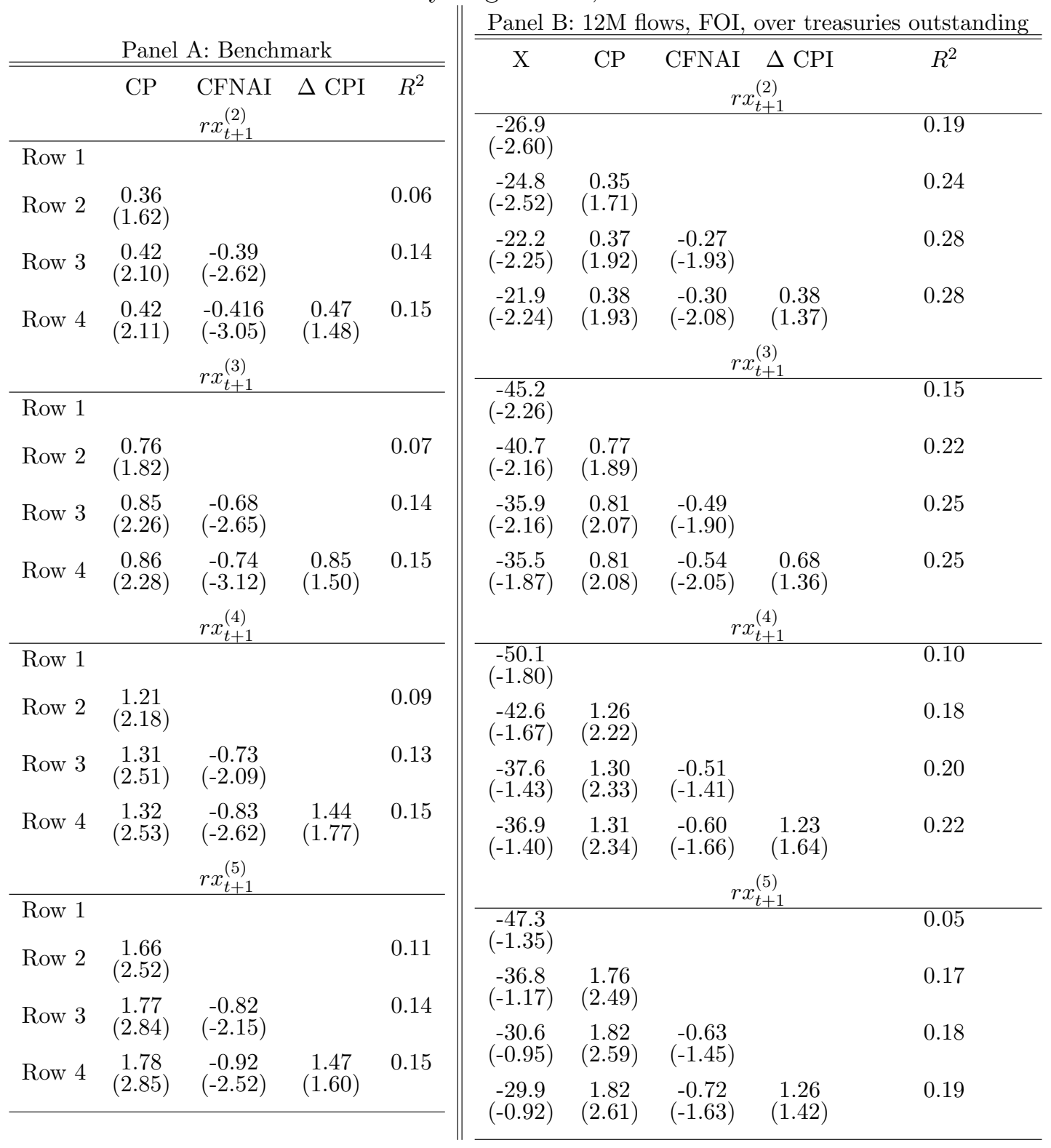

Notes: $\mathrm{X}$ is 12 month cumulated net purchases of Treasury notes and bonds by FOI normalized by total marketable treasuries outstanding. CP is Cochrane-Piazzesi factor. CFNAI is the Chicago Fed National Activity Index. $\Delta$ CPI the log change in the consumer price index. Regressions include a constant. First line of each row is OLS coefficient, Second line is t-stat Newey-West (12 lags). Sample Dec 1994-Dec 2010 
Table 9: Monthly Regressions, Dec1994-Dec2010

\begin{tabular}{|c|c|c|c|c|c|c|c|c|c|}
\hline \multicolumn{5}{|c|}{ Panel A: Benchmark } & \multicolumn{5}{|c|}{ Panel B: $12 \mathrm{M}$ flows, FOI, over treasuries outstanding } \\
\hline & $\mathrm{CP}$ & CFNAI & $\Delta \mathrm{CPI}$ & $R^{2}$ & $\mathrm{X}$ & $\mathrm{CP}$ & CFNAI & $\Delta \mathrm{CPI}$ & $R^{2}$ \\
\hline \multicolumn{5}{|c|}{$\overline{r x}_{t+1}$} & \multicolumn{5}{|c|}{$\overline{r x}_{t+1}$} \\
\hline Row 1 & & & & & $\begin{array}{l}-42.38 \\
(-1.82)\end{array}$ & & & & 0.10 \\
\hline Row 2 & $\begin{array}{l}1.00 \\
(2.17)\end{array}$ & & & 0.09 & $\begin{array}{l}-36.20 \\
(-1.71)\end{array}$ & $\begin{array}{c}1.04 \\
(2.21)\end{array}$ & & & 0.19 \\
\hline Row 3 & $\begin{array}{l}1.08 \\
(2.55)\end{array}$ & $\begin{array}{c}-0.65 \\
(-2.33)\end{array}$ & & 0.14 & $\begin{array}{l}-31.57 \\
(-1.45)\end{array}$ & $\begin{array}{l}1.08 \\
(2.34)\end{array}$ & $\begin{array}{c}-0.48 \\
(-1.60)\end{array}$ & & 0.21 \\
\hline Row 4 & $\begin{array}{l}1.09 \\
(2.56)\end{array}$ & $\begin{array}{c}-0.72 \\
(-2.80)\end{array}$ & $\begin{array}{l}1.06 \\
(1.64)\end{array}$ & 0.15 & $\begin{array}{l}-31.03 \\
(-1.43)\end{array}$ & $\begin{array}{l}1.08 \\
(2.36)\end{array}$ & $\begin{array}{c}-0.54 \\
(-1.79)\end{array}$ & $\begin{array}{c}0.89 \\
(1.48)\end{array}$ & 0.22 \\
\hline
\end{tabular}

Notes: $\mathrm{X}$ is 12 month cumulated net purchases of Treasury notes and bonds by FOI normalized by total marketable treasuries outstanding. CP is Cochrane-Piazzesi factor. CFNAI is the Chicago Fed National Activity Index. $\Delta$ CPI the log change in the consumer price index. Regressiones include a constant. First line of each row is OLS coefficient, Second line is t-stat Newey-West (12 lags). Sample Dec 1994-Dec 2010 